\title{
Navigating motivation: a semantic and subjective atlas of 7 motives
}

\section{Article}

Published Version

Creative Commons: Attribution 4.0 (CC-BY)

Open Access

Chierchia, G., Przyrembel, M., Lesemann, F. P., Bosworth, S. ORCID: https://orcid.org/0000-0002-8978-9516, Snower, D. and Singer, T. (2021) Navigating motivation: a semantic and subjective atlas of 7 motives. Frontiers in Psychology, 11. 568064. ISSN 1664-1078 doi: https://doi.org/10.3389/fpsyg.2020.568064 Available at https://centaur.reading.ac.uk/95188/

It is advisable to refer to the publisher's version if you intend to cite from the work. See Guidance on citing.

To link to this article DOI: http://dx.doi.org/10.3389/fpsyg.2020.568064

Publisher: Frontiers Media

All outputs in CentAUR are protected by Intellectual Property Rights law, including copyright law. Copyright and IPR is retained by the creators or other copyright holders. Terms and conditions for use of this material are defined in the End User Agreement.

\section{www.reading.ac.uk/centaur}

\section{CentAUR}


Central Archive at the University of Reading

Reading's research outputs online 


\section{OPEN ACCESS}

Edited by:

Alessia Celeghin

University of Turin, Italy

Reviewed by:

Andreas Keil,

University of Florida, United States

Pilar Ferré Romeu,

University of Rovira i Virgili, Spain

*Correspondence:

Marisa Przyrembel

marisa.przyrembel

@akkon-hochschule.de

Gabriele Chierchia

gsc34@cam.ac.uk

†These authors have contributed equally to this work and share first authorship

Specialty section:

This article was submitted to

Emotion Science,

a section of the journal

Frontiers in Psychology

Received: 31 May 2020

Accepted: 28 December 2020

Published: 27 January 2021

Citation:

Chierchia G, Przyrembel M Lesemann FP, Bosworth S, Snower D and Singer $T$ (2021) Navigating Motivation: A Semantic and Subjective Atlas of 7 Motives.

Front. Psychol. 11:568064. doi: 10.3389/fpsyg.2020.568064

\section{Navigating Motivation: A Semantic and Subjective Atlas of 7 Motives}

\author{
Gabriele Chierchia ${ }^{1 * \dagger}$, Marisa Przyrembel ${ }^{2 *}$, Franca Parianen Lesemann ${ }^{3}$, \\ Steven Bosworth ${ }^{4}$, Dennis Snower ${ }^{5,6}$ and Tania Singer ${ }^{7}$ \\ ${ }^{1}$ Department of Psychology, University of Cambridge, Cambridge, United Kingdom, ${ }^{2}$ Akkon University of Applied Sciences \\ for Human Sciences, Berlin, Germany, ${ }^{3}$ Helmholtz Institute, Utrecht University, Utrecht, Netherlands, ${ }^{4}$ University of Reading, \\ Reading, United Kingdom, ${ }^{5}$ Department of Economics, Hertie School of Governance, Berlin, Germany, ${ }^{6}$ Blavatnik School of \\ Government, Oxford, United Kingdom, ${ }^{7}$ Social Neuroscience Lab, Max Planck Society, Berlin, Germany
}

Research from psychology, neurobiology and behavioral economics indicates that a binary view of motivation, based on approach and avoidance, may be too reductive. Instead, a literature review suggests that at least seven distinct motives are likely to affect human decisions: "consumption/resource seeking," "care," "affiliation," "achievement," "status-power," "threat approach" (or anger), and "threat avoidance" (or fear). To explore the conceptual distinctness and relatedness of these motives, we conducted a semantic categorization task. Here, participants were to assign provided words to one of the motives. By applying principal component analysis to the categorization assignments we represent the semantic inter-relations of these motives on a two-dimensional space, a "semantic atlas." This atlas suggests that, while care and affiliation are conceptually close, affiliation is closer to threat avoidance (or fear); opposite to these motives we find achievement, consumption and power, with the latter lying closer to threat approach (or anger). In a second study, we asked participants to rate how well the motive-specific words obtained in the first study described their currently experienced feelings. We find that semantically close motives are also more likely to be experienced together, that is, we replicate most of the semantic relations in the "subjective atlas." We discuss our findings in comparison to other multi-dimensional models of motivation, which show clear similarities. In addition to these motivational atlases, we provide a database of motive-specific words, together with the valence and arousal scores. These can be used for future research on the influence of motives on decision making.

Keywords: affiliation, care, motives, motivation psychology, semantic categorization, economic decision making

\section{INTRODUCTION}

Standard economic theory is typically agnostic with regards to the types of goals that agents generally pursue and assumes that agents are systematically driven only by stable preferences (Samuelson, 1938; Stigler and Becker, 1977). In contrast, decades of psychological research have suggested that many decisions are driven by particular motives, such as the motivation for achievement, power or affiliation (Thorndike, 1898; McDougall, 1932; Lewin, 1935; McClelland et al., 1953; Mowrer, 1960; Deci and Moller, 2005; Heckhausen and Heckhausen, 2010). In line with this, natural languages present a highly rich and structured vocabulary of motive-related words (Talevich et al., 2017). These motives are typically conceived both as trait-related dispositions and as 
context-sensitive states that lead subjects to experience particular types of incentives as pleasurable and rewarding, to strive for certain types of goals, and hence to activate particular behavioral tendencies and related decisions (Atkinson, 1964; McClelland, 1965; Emmons and McAdams, 1991; Pang, 2010; Rheinberg and Engeser, 2010; Schultheiss and Strasser, 2012). Similarly, recent advances in neurobiology have also begun to move beyond classic approach/avoidance interpretations of motivation, which have been prevalent in the field of biology, enriching it with a more motive-related vocabulary such as power-status (e.g., Eisenegger et al., 2011; Terburg and van Honk, 2013), affiliation (e.g., Feldman, 2012) and care (e.g., Alcaro and Panksepp, 2011; Valk et al., 2017). Finally, behavioral game theorists (e.g., Camerer, 2003), social dilemma researchers (Dawes, 1980; Kollock, 1998; Fehr and Fischbacher, 2003; van Lange et al., 2013) and neuroeconomists (Glimcher et al., 2013) have also documented that humans often pursue ends other than the maximization of their own payoff in economic interactions (Frank, 1988; Loewenstein and O'Donoghue, 2004), and have, for example, incorporated status-related or altruistic preferences in utility functions to characterize such behaviors (e.g., Loewenstein et al., 1989; Robson, 2001; Sally, 2001; Fehr and Fischbacher, 2003; Fehr et al., 2013).

To lay the grounds of an integrated motive-based framework for decision making, we first reviewed the literature in the domains of motivation psychology, neurobiology as well as behavioral economics. This review is summarized in Table 1. Based on this review, we converged on a preliminary set of six motives that pertain to motivation psychology or neurobiology and that are likely relevant for economic decision making: achievement, power-status, affiliation, care, threat avoidance (anger), threat approach (fear). In addition, moving from economics toward psychology, consumption is proposed as an exploratory seventh motive in psychology to potentially parallel the benchmark form of utility typically used in economic research. Of these seven preliminary motives, power, affiliation and achievement are classic well-known motives in motivation psychology (Table 1), whereas power and affiliation have also more recently begun to be studied in neurobiological research. Fear (or threat avoidance) and anger (threat approach) are prominent in both motivation psychology and neurobiology, care is a term used mostly in neurobiology (Table 1).

Naturally, the short review summarized in Table $\mathbf{1}$ is far from exhaustive and the list of seven preliminary motives is unlikely conclusive either. Yet, these motives have been identified to be relevant for the three fields of interest reviewed here and should provide sufficiently important and diverse steppingstones from which in future research on other related motives could be investigated. Rather than justifying the selection of these particular set of motives, the aim of this work is 2-fold: first, we aim to investigate how these seven relevant motives are related to each other-which of these motives are conceptually and/or experientially similar or different to each other? Which emerge together and which are rather antagonistic to each other? Second, we aim at providing a database of motive-specific words that may be used in future studies to more specifically probe the role of distinct motives in economic decision making.
To achieve these two goals we conducted two studies. First, we follow seminal efforts in the emotion literature (e.g., Russell, 1980) and investigate the semantic relations of the seven identified motives. We do so by asking whether and how subjects coherently differentiate between these motives in a semantic categorization task. By applying principle component analysis to such categorization judgments, we then further explore which dimensions might allow them to do so. In a second study, we assess whether the observed semantic inter-relations hold at the level of subjective experience, that is, whether semantically "close" motives are also more likely to co-occur in subjectively reported experience. In what follows, we begin by briefly introducing the seven motives of interests. We then pass to describing the two empirical studies and conclude by providing a database of motivespecific words.

\section{Motives in Motivation Psychology}

Three motives, namely, "achievement," "power," and "affiliation" are among the most recognized motives in motivation psychology (Weiner, 1990). Achievement has been defined as the desire to do something better or more efficiently than before (McClelland et al., 1953; Atkinson and Feather, 1966; Weiner, 1990; Heckhausen and Heckhausen, 2010) or as "the need to feel that one is making progress toward important and/or long term goals" (Apter et al., 1998, p. 9). A power and/or status-seeking motive can be understood as the desire to have an impact (Fodor and Riordan, 1995; Schultheiss and Brunstein, 2010), to be strong, to influence others (McClelland et al., 1953; Reiss, 2004; Heckhausen and Heckhausen, 2010). It has also been described as "the need to be in control of objects, situations and events, to dominate people" (in Apter's “autic mastery," Apter et al., 1998, p. 9). Affiliation has been defined as the need to be liked or the need to belong (Murray, 1938; McClelland et al., 1953; Jackson, 1974; Baumeister and Leary, 1995; Heckhausen and Heckhausen, 2010), and many have distinguished this from a Care related motive, which is rather related to accepting and nourishing others. For instance, Murray (1938) contrasts nurturance and affiliation, McAdams (1980) distinguishes an intimacy motivation from affiliation, Heckhausen (2000) discriminates affiliation vs. altruism/help, Jackson (1974) distinguishes between affiliation and nurturance, Apter et al. (1998) differentiates between autic sympathy ("the need to be admired, to be attractive to others, popular or loved," p. 9) and alloic sympathy ("the need to care for, nurture, give to others, to enjoy the pleasure others receive from this," p. 9), and Schwartz's system of universal values distinguishes benevolence and universalism from conformity (Schwartz and Boehnke, 2004).

In addition to classical motives such as achievement, power and affiliation discussed in motivation psychology, many have advocated a motivational threat system encompassing fear and anger. For example, fear-related motives have been described as harm avoidance (Murray, 1938), avoidance (Thorndike, 1898; Lewin, 1935; Hull, 1943), fear (H. Heckhausen, 1989), anxiety (Trudewind, 2000), security (Schwartz and Boehnke, 
TABLE 1 | Motives across disciplines.

\begin{tabular}{|c|c|c|}
\hline & Psychology & Neurobiology \\
\hline $\begin{array}{l}\text { Consumption/ } \\
\text { Resource-seeking }\end{array}$ & $\begin{array}{l}\text { Foraging, ownership (McDougall, } \\
\text { 1932) } \\
\text { Hedonism (Schwartz and Boehnke, } \\
\text { 2004) }\end{array}$ & $\begin{array}{l}\text { Wanting/appetitive; desire-seeking; foraging } \\
\text { (Berridge and Robinson, 1998; Depue and } \\
\text { Collins, 1999; Ikemoto and Panksepp, 1999; } \\
\text { Lea and Webley, 2006; Panksepp, 2006; } \\
\text { Alcaro et al., 2007; de Waal, 2007; Schultz, } \\
\text { 2007; Delgado et al., 2008; Berridge et al., } \\
\text { 2010) } \\
\text { Lust and play (Nelson and Panksepp, 1998; } \\
\text { Panksepp, 2005; Alcaro and Panksepp, } 2011\end{array}$ \\
\hline Care & $\begin{array}{l}\text { Intimacy (McAdams, 1980) } \\
\text { (Weinberger et al., 2010) } \\
\text { Nurturance (Murray, 1938; } \\
\text { Weinberger et al., 2010) } \\
\text { Pro-social altruism (Heckhausen, } \\
\text { 2000) } \\
\text { Help (Heckhausen, 1989) } \\
\text { Idealism and family (Reiss, 2004) } \\
\text { Compassion (Weinberger et al., 2010) }\end{array}$ & $\begin{array}{l}\text { Care (Nelson and Panksepp, 1998; Panksepp } \\
\text { 2005; Alcaro and Panksepp, 2011) } \\
\text { Maternal love/parental care (Bartels and Zeki, } \\
\text { 2004; Strathearn et al., 2009) } \\
\text { Loving-kindness and compassion (Klimecki } \\
\text { et al., 2012, 2014; Weng et al., 2013; Engen } \\
\text { and Singer, 2015; Bornemann et al., 2016; } \\
\text { Hildebrandt et al., 2017; Valk et al., 2017) } \\
\text { Trust (Bos et al., 2012; Boksem et al., 2013) }\end{array}$ \\
\hline
\end{tabular}

Alloic sympathy (Apter et al., 1998)

Benevolence (Schwartz and

Boehnke, 2004)

\section{Affiliation}

Need to be liked or the need to belong (Murray, 1938; McClelland et al., 1953; Jackson, 1974; Weiner, 1990; Baumeister and Leary, 1995; Heckhausen and Heckhausen, 2010) Autic sympathy (Apter et al., 1998) Conformity (Schwartz and Boehnke, 2004)

Power-Status

Power/status-seeking (Weiner, 1990; Schwartz and Boehnke, 2004) Having impact (Fodor and Riordan, 1995; Schultheiss and Brunstein, 2010)

Being strong and influencing others (McClelland et al., 1953; Reiss, 2004; Heckhausen and Heckhausen, 2010) Agency/Power (Diehl et al., 2004; Abele et al., 2008) 2001; Ross and Young, 2009; Gordon et al., 2011; Feldman, 2012; McCall and Singer, 2012; Bakermans-Kranenburg and van ljzendoorn, 2013; Rilling, 2013) (Fear of) social rejection (Eisenberger et al., 2003; Eisenberger, 2012)

Tend and befriend (Taylor, 2006) Norm compliance, social influence and peer 2009; Chein et al., 2011; Zaki et al., 2011; Izuma and Adolphs, 2013; Ruff et al., 2013; van Hoorn et al., 2016) Mazur and Booth, 1998; Salvador, 2005; et al., 2015; Reimers and Diekhof, 2015; Dreher et al., 2016; Carré and Archer, 2018; Bird et al., 2019)
Achievement/being better or more efficient than before (McClelland et al., 1953; Atkinson and Feather, 1966; Weiner, 1990; Schwartz and Boehnke, 2004; Heckhausen and Heckhausen, 2010)

\section{Economics}

Utility (Samuelson, 1938; Stigler and Becker, 1977) In experimental economic settings, a benchmark utility function is frequently assumed to depend only on monetary or material payoffs (Camerer, 2003) Speculative psychological and neurobiological correspondents of such a benchmark interpretation of utility are presented on the left side of this row

Altruism (Hamilton, 1964; Becker, 1974; Palfrey and Rosenthal, 1988; Andreoni, 1990; Bruce and Waldman, 1990; Sally, 2001; Fehr and Fischbacher, 2003)

Generosity in GTPs and charitable donations (Harbaugh et al., 2007; Small and Lerner, 2008; Eimontaite et al., 2013; Polman and Kim, 2013; Böckler et al., 2016;

Tusche et al., 2016) Trust in GTPs (Kosfeld et al., 2005; Baumgartner et al., 2008; Singer and Steinbeis, 2009; Böckler et al., 2016; Chierchia et al., 2017)

Cooperation in GTPs (Batson and Moran, 1999; Batson and Ahmad, 2001; Fehr and Fischbacher, 2004; Small and Lerner, 2008; Eimontaite et al., 2013; Polman and Kim, 2013; Chierchia et al., 2017; Bartke et al., 2019) Decreased punishment in GTPs (Batson and Ahmad, 2001; Singer and Steinbeis, 2009; McCall et al., 2014; Kirk et al., 2016)

Social bonding (Carter, 1998; Insel and Young, influence (Spitzer et al., 2007; Klucharev et al.,

Competition/dominance (Wingfield et al., 1990; Burnham, 2007; Eisenegger et al., 2010, 2011; Hall et al., 2010; Stanton et al., 2011; Apicella

Neurobiological research on achievement-related behaviors remains sparse
Social identity influence economic outcomes (Akerlof and Kranton, 2000)

Norm-based cooperation and punishment in GTPs (Fehr and Fischbacher, 2004; Carpenter and Matthews, 2009; Fehr and Schurtenberger, 2018) Ingroup cooperation and outgroup punishment in GTPS (Bernhard et al., 2006; Balliet et al., 2014; Yamagishi and Mifune, 2016)

Increased generosity in GTPs in response to social evaluation cues (Hoffman et al., 1996; Takahashi et al., 2007; Ekström, 2012; von Dawans et al., 2012; Winking and Mizer, 2013)

Conformism in GTPs and economic decision making (Shang and Croson, 2009; van Hoorn et al., 2016; Charness et al., 2019; Dimant, 2019)

Status and power concerns (Frank, 1985; Cole et al., 1992; Robson and Samuelson, 2011)

Punishment in GTPs (Straub and Murnighan, 1995; Yamagishi et al., 2012; Gordon and Lea, 2016; Chierchia et al., 2017)

Status/image-based cooperation and generosity or withdrawal from cooperation in GTPs (Wedekind and Milinski, 2000; Hardy and Van Vugt, 2006; Lammers et al., 2008; Kumru and Vesterlund, 2010; Guinote et al., 2015)

Risk taking (Anderson and Galinsky, 2006; Apicella et al., 2015) Impatience in temporal discounting (Joshi and Fast, 2013)

Pursuing subjective goals and striving for success (Kahneman and Tversky, 1979; Selten, 1998; Gilboa and Schmeidler, 2001; Gómez-Miñambres, 2012) 
TABLE 1 | Continued

\begin{tabular}{|c|c|c|c|}
\hline & Psychology & Neurobiology & Economics \\
\hline & $\begin{array}{l}\text { Agency/Achievement (Diehl et al., } \\
\text { 2004; Abele et al., 2008) } \\
\text { Competence (Fiske et al., 2007; } \\
\text { Cuddy et al., 2008) } \\
\text { Mastery (Apter et al., 1998) }\end{array}$ & & \\
\hline $\begin{array}{l}\text { Fear/Threat } \\
\text { avoidance }\end{array}$ & $\begin{array}{l}\text { Fear/Threat avoidance (Epstein, } \\
\text { 1972; Heckhausen, 1989; Carver and } \\
\text { Harmon-Jones, 2009) } \\
\text { Harm avoidance (Murray, 1938) } \\
\text { Avoidance (Thorndike, 1898; Lewin, } \\
\text { 1935; Hull, 1943) } \\
\text { Anxiety (Trudewind, 2000) } \\
\text { Security (Schwartz and Boehnke, } \\
\text { 2004) }\end{array}$ & $\begin{array}{l}\text { Fear/Threat avoidance (Nelson and Trainor, } \\
\text { 2007; Siever, 2008; Rodrigues et al., 2009; } \\
\text { Bond and Wingrove, 2010; Potegal and } \\
\text { Stemmler, 2010; Adolphs, 2013; Barrett and } \\
\text { Russell, 2014) } \\
\text { Fear/panic (Nelson and Panksepp, 1998; } \\
\text { Panksepp, 2005, 2006; Alcaro and Panksepp, } \\
\text { 2011) } \\
\text { Punishment/reinforcement learning (O'Doherty } \\
\text { et al., 2001; Dayan and Balleine, 2002; } \\
\text { Montague et al., 2004; Schultz, 2007; Seymour } \\
\text { et al., 2007; Rangel et al., 2008; Seymour and } \\
\text { Dolan, 2008; Bromberg-Martin et al., 2010; } \\
\text { Lang and Bradley, 2010; Dayan and Berridge, } \\
\text { 2014) }\end{array}$ & $\begin{array}{l}\text { Risk aversion, loss aversion and ambiguity aversion } \\
\text { (Raghunathan and Pham, 1999; Lerner and Keltner, } \\
\text { 2001; Maner and Gerend, 2007; Porcelli and Delgado, } \\
\text { 2009; de Martino et al., 2010; Hartley and Phelps, 2012; } \\
\text { Canessa et al., 2013; Schulreich et al., 2016) }\end{array}$ \\
\hline $\begin{array}{l}\text { Anger/Threat } \\
\text { approach }\end{array}$ & $\begin{array}{l}\text { Anger/Threat approach (Carver and } \\
\text { Harmon-Jones, 2009) } \\
\text { Aggression (Heckhausen, 1989) } \\
\text { Rage (McDougall, 1932) } \\
\text { Vengeance (Reiss, 2004) }\end{array}$ & $\begin{array}{l}\text { Anger/Threat approach (Nelson and Trainor, } \\
\text { 2007; Siever, 2008; Rodrigues et al., 2009; } \\
\text { Bond and Wingrove, 2010; Potegal and } \\
\text { Stemmler, 2010; Adolphs, 2013; Barrett and } \\
\text { Russell, 2014) } \\
\text { Rage (Nelson and Panksepp, 1998; Panksepp, } \\
\text { 2005, 2006; Alcaro and Panksepp, 2011) }\end{array}$ & $\begin{array}{l}\text { Punishment in GTPs (Pillutla and Murnighan, 1996; } \\
\text { Andrade and Ariely, 2009; Seip et al., 2014; Gummerum } \\
\text { et al., 2016; Liu et al., 2016) } \\
\text { Withdrawal from cooperation in GTPs (Dunn and } \\
\text { Schweitzer, 2005; Polman and Kim, 2013; Motro et al., } \\
\text { 2016) } \\
\text { Risk taking (Raghunathan and Pham, 1999; Lerner and } \\
\text { Keltner, 2001; Fessler et al., 2004; Tsai and Young, 2010; } \\
\text { Kugler et al., 2012; Ferrer et al., 2017; She et al., 2017) }\end{array}$ \\
\hline
\end{tabular}

GTPS, game theoretical paradigms.

2004), while anger-related motives have been characterized as aggression (Heckhausen, 1989), negativism (Apter et al., 1998), rage (McDougall, 1932; Panksepp, 2006), and vengeance (Reiss, 2004). Naturally, fear and anger also bare the names of primary emotions, though emotion researchers have frequently highlighted their motivational components (Roseman, 2011, calls them "emotivations") and related them to "threat approach" and "threat avoidance" (Carver and Harmon-Jones, 2009). Finally, the optimization of one's own utility and welfare, which plays a prominent role in economics, is often operationalized as the self-interested accumulation of goods (e.g., as monetary payoff in behavioral economics settings). This has no clear correspondent in psychology (but see Kasser, 2006; Kasser et al., 2014). However, a possibly related motivational value called hedonism has been suggested by Schwartz and Boehnke (2004), and defined as "pleasure or sensuous gratification for oneself (pleasure, enjoying life, self-indulgent)" (p. 239). Moreover, a consumption motive has also been associated with terms such as wanting, desire-seeking, or foraging and ownership (McDougall, 1932), especially in the animal and neurobiological literature (Berridge and Robinson, 1998; Depue and Collins, 1999; Ikemoto and Panksepp, 1999; Lea and Webley, 2006; Panksepp, 2006; de Waal, 2007; Delgado et al., 2008; Berridge et al., 2010).

\section{A Semantic and Subjective Atlas of Seven Motives}

As a first step toward investigating the relations between these motives, we conducted a semantic categorization task in which we asked subjects to ascribe a number of motive-related words to the seven motivational categories posited above. This approach draws from a tradition of psychological studies on emotions that assesses subjects' conceptualization of affective states (Kuppens et al., 2013, for a review). For instance, in a seminal paper, Russell (1980) asked subjects to categorize 28 emotion-related words to pre-defined emotional categories and found that 2 dimensions, namely valence and arousal, could predict most categorization judgments (see also Posner et al., 2005; Kuppens et al., 2013). In line with this, many psychologists (e.g., Shaver et al., 1987; Barrett, 2004) have capitalized on categorization agreements/disagreements to spatially represent "closeness" of emotion-related concepts on a single (multidimensional) space. To our knowledge, these approaches have frequently been applied to emotions, but not to the motives addressed here.

Importantly, Russell (1980) argues that the cognitive structure of emotions should reflect the structure of actually experienced emotions, but this needn't always be the case. For instance, compassion tends to be prototypically conceptualized as a positive emotion, though when experienced (e.g., when 
observing a suffering other) it can be accompanied by positive as well as negative affect (Condon and Feldman Barrett, 2013). We thus asked whether the conceptual-semantic proximity of motives could predict their experienced proximity (e.g., an increased likelihood of co-occurrence)? To answer this question, in a second study, we asked participants to rate how well the motives of interest described their currently (spontaneously) experienced motives and feelings.

In terms of the expected relations between these motives, achievement and power are likely to be related, as are affiliation and care. In fact, a long standing tradition places power and achievement-related constructs within an "agency" dimension of behavioral orientation (which refers to a person's striving to be independent, to control one's environment, and to assert, protect and expand one's self), sometimes with achievementrelated states on one end of this hypothetical agency spectrum, and power-related states on the other (Bakan, 1966; Diehl et al., 2004; Abele et al., 2008). The same tradition incorporates care and affiliation-themed constructs within a "communion" dimension (which refers to a person's striving to be part of a community, to establish close relationships with others, and to subordinate individual needs to the common good) (Bakan, 1966; Camille et al., 2004; Abele et al., 2008) and has frequently illustrated a gradient within this dimension, spanning notions related to care, on one side, to those related to "lack of independence" (i.e., affiliation), on the other (Abele et al., 2008). Similarly to this agency/communion tradition, Apter et al. (1998) proposes the meta-motivational distinction between mastery, which encompasses elements of power and achievement, and sympathy, which includes affiliation and care-themed states. Furthermore, Schwartz's system of universal values also finds that conformity and benevolence are contiguous values, in that their pursuit is not mutually exclusive, as is the case for power and achievement (Schwartz and Boehnke, 2004).

Second, we expected that words attributed to affiliation would have more conceptual proximity to fear, as research on affiliation has made a link between the need to belong and fear of rejection, social pain and separation distress (Panksepp, 2006; Weinberger et al., 2010; Eisenberger, 2012). In contrast, we also expected words related to care to be relatively farther from fear, since research on empathic concern distinguishes between care-related motives and negatively valenced states such as empathic distress (Batson et al., 1983, 1987).

Third, we expected words related to threat approach (i.e., anger) and threat avoidance (i.e., fear) to be relatively close. In fact, both motives are typically associated with high arousal and negative affect, and both are related to perceived threats (Lerner et al., 2015). Moreover, as anger has been associated with feelings of agency (e.g., approach or fight-related responses) (Carver and Harmon-Jones, 2009), we expected it to be closer to power and achievement than threat avoidance (typically associated with avoidance or flight).

Finally, as consumption was thought of as a parallel to the self-interested motivation traditionally assumed in economics, we expected consumption-specific words to be relatively close to agentic motives such as achievement or power/status and distant from words related to care.

\section{STUDY 1}

\section{Methods}

\section{Participants and Procedures}

Seventy nine participants (40 males, mean age $=32.4, \mathrm{SD}$ $=13$ ) took part in the study over 10 experimental sessions. Sessions were conducted in the computer lab of the Department of Social Neuroscience at the Max Planck Institute in Leipzig, Germany. Participants took part in the tasks from individually shielded computer cubicles. Participants of sessions 1 through $6(n=38,21$ males, mean age $=41.3, \mathrm{SD}=18.2)$ took part in the categorization task only (see below), while participants of sessions 7 through $10(n=41,20$ males, mean age $=26.4$, SD $=3.8$ ) additionally took part in the valence and arousal ratings (after the categorization task). Each participant took part in only one session and sessions were scheduled based on participant availability over a 2-month period. Experimental protocols were approved by local ethics committee (of the Medical Faculty of the University of Leipzig, n. 090-15-090032015) and all participants provided written informed consent for the anonymized treatment of their data.

\section{Word Pre-selection}

To pre-select motive-related words to use in the categorization task, we drew from a previously existing "free-association" database (Nelson et al., 2004), which was created by requiring participants to name the "first word that came to mind that was meaningfully related or strongly associated to the presented cue word." This database provides over 72.000 "cue-associate" pairs. To draw motive-related words from this database we proceeded in two steps. First, for each of our motives, we searched the database for one or two most closely related words. We called these "anchor words." Second, we searched the database for adjectives that had been associated to the anchor words in either the 1st or 2nd degree. For example, for our care motive we selected among associates of the anchor word "care" (1st degree), as well as among the associates of these associates-2nd degree. For most of our motives, the identification of anchor words was trivial. Specifically, we took the word "care" as an anchor word for the care motive, the word "power" for power-status, "fear and fearful" for threat avoidance (i.e., fear), "anger/angry" for threat approach (i.e., anger) and "achieve/achievement" for achievement. Two of the posited motives, namely, "affiliation" and "consumption," did not have obvious equivalents in the database. For affiliation we thus chose the anchor words "friend/friendly," while for consumption we chose the anchor word "want." After having obtained a preliminary set of motive-associated words, we expanded this set through online synonym vocabularies.

\section{Semantic Categorization Task}

The pre-selected words were then used in the main categorization task of interest. Here, subjects were required to ascribe each word to one of the seven motives posited by our framework. Visually, participants were shown a list of candidate motive-related words (in randomized order), on the left side of the screen, and seven labeled "boxes" on the right (see Supplementary Figure 1). All 
box labels began with the phrase "motivated by..." and ended with one of the following: "...care for others," "... the desire to belong," “... power," “... achievement," “... anger," “... fear," and "...the desire for possession and consumption". Subjects were then asked to drag and drop each word into one (and only one) of the boxes. A list of 174 words was used in sessions 1 through 6. After session 6, finding that participants quickly accustomed to the task and easily managed to complete it in the allotted time, we increased the number of words to increase our power. Specifically, participants of the remaining sessions (sessions 7 through 10) assessed a longer list of 304 words. With one exception (due to a programming error for the word "gemein" = mean), all of the words used in the first list were also used in the second. All participants assessed all of the words.

\section{Valence, Arousal, and Frequency Scores}

After the categorization task, participants of sessions 7 through $10(n=41)$ also rated each of the 304 words on two scales: a valence scale and an arousal scale. Scales consisted of visual analog scales, which could take values between 0 and 100 (in Supplementary Table 1 we subtract 50 from the mean valence and arousal scores, so that $t$-tests against 0 may suggest which words are statistically high/low in valence or arousal). Valence and arousal scales were altered relative to more commonly used ones in emotion research (e.g., scales from 1 to 9) (Bradley and Lang, 1999) to allow for greater variance in responses, for consistency with the self-report scales of study 2 (see below) and because we mainly intended to use such scales in a PCA that standardizes all measures to eliminate scale-specific variance. The instructions for the tasks were taken from Kanske and Kotz (2010). English translations in Supplementary Table 1 were carried out by professional translators.

\section{Analysis}

We ran two types of analyses. The first searched for "motivespecific" words, that is, words that were attributed more frequently to one motive than any other. To obtain these, for each word, we took the two categories in which the word had been most frequently placed in and we then ran a chisquare test to assess whether the resulting proportion could be due to chance. If this test was significant $(p<0.05)$, this indicates that assignment frequencies differed between the most popular and second-most popular categories (and thus also between the most popular category and the third-most popular category, the fourth-most popular etc.). We considered words surpassing this test to be "motive-specific," because they were more frequently assigned to one category than any other, and we took words to be "ambiguous" otherwise. $P$-values were also corrected for multiple comparisons (using the Hochberg method). In Supplementary Table 1, we append an asterisk to the words that survived this more stringent criterion. This could be considered a statistical parallel to Russell's "precision" (which took a value of 0 , if a given word was distributed randomly

\footnotetext{
${ }^{1}$ For sessions 6 through 10, we slightly changed the label of this category to "motivated by wanting." We did so to control for a possible overly negative connotation of the words consumption and possession. This label change led to no identifiable difference in the results.
}

over the provided categories, and 1, if all subjects attributed a given word to the same category) (Russell, 1980). Second, we ran a principle component analysis (PCA) taking the seven motivation-categories as variables/descriptors, and the single words as items. The PCA was conducted with the PCA function of the "Factominer" package (Lê et al., 2008) in R (R-CoreTeam, 2014). The PCA was based on the correlation matrix of the standardized variables and it used unrotated principle components. As supplementary variables of interest we took: (i) the results of the first analysis (namely, a vector indicating which motive-if any-each word had been specifically ascribed to); and (ii) valence and arousal scores. Supplementary variables enable to relate variables to PCA space, without affecting its solution (Lê et al., 2008).

\section{Results}

\section{Motive Specific Words}

For each one of the tested motives, we found a subset of words that significantly $(p<0.05)$ differentiated this motive from each of the other presented motives. This was observed for 213 (70\%) of the 304 words and an average of 30 words ( $\mathrm{SD}=8.28)$ per motivational category. This suggests that participants displayed on which words best characterize each of the seven distinctions we proposed. The "motive-specific" words are presented in the database (Supplementary Table 1). Within each motivational category they are ordered based on how frequently they were placed in that category.

\section{Semantic Closeness of Seven Motives}

To explore the relative "semantic distance" between motives we ran a PCA on the categorization judgments. The Kaiser rule suggested retaining the first 2 components (as these had eigenvalues higher than unity) of the PCA. The first component explained $25.7 \%$ of the categorization variance, the second $18.7 \%$, for a total of $44.4 \%$. The 1 st component most clearly separated between affiliation, care and fear, on the one side, and power, achievement, and consumption on the other (all scores were below -0.3 and above 0.3 , respectively). The 2 nd component distinguished between anger and fear, on the one side, and care, consumption and achievement on the other (all scores above 0.4 and below -0.3 , respectively) (see Figure 1, left). With regard to the supplementary valence and arousal variables, valence was correlated to both the PCA components, but more strongly to component 2 ( $r=0.54, p<0.001)$, while arousal was not clearly related to either of the dimensions (both $r_{s}<0.21$ ).

\section{STUDY 2}

\section{Methods}

\section{Participants}

Participants $(n=310$, mean age $=27.19$, sd $=5.97$, females $=163$, males $=147$ ) were recruited via email through the Max Planck participant database to take part in two separate studies on economic decision making (Chierchia et al., 2017, 2021). Those studied required a larger sample size than study 1 , yet they provided a good opportunity to test these hypotheses 


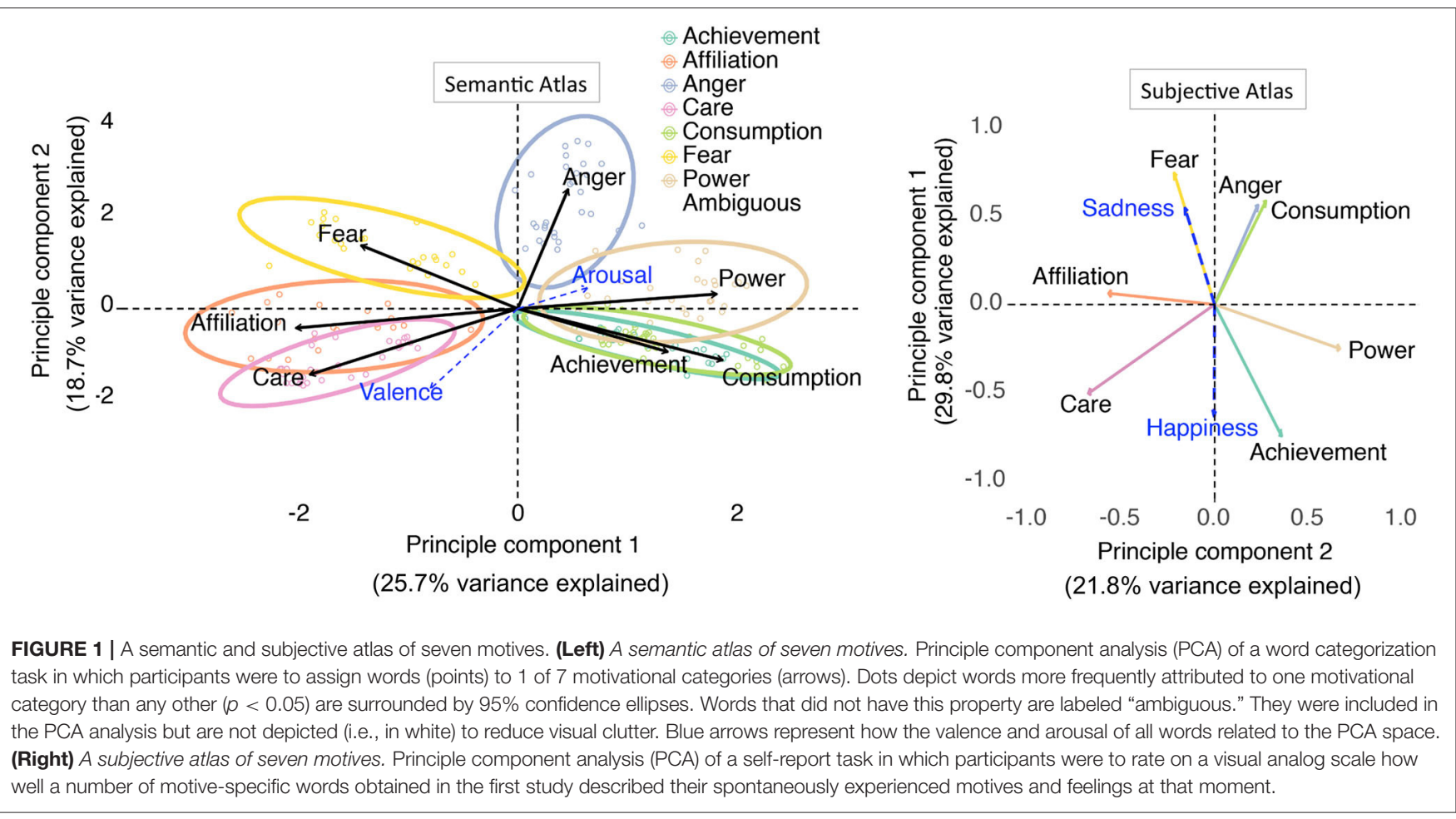

as well. The higher sample size of study 2, is thus just a byproduct of this incidental annexation. As soon as participants were welcomed to the experimental sessions, and thus before being introduced to any of the experimental activities of interest for those studies, they took part in the task described below. Assessments were approved by the Research Ethics Committee (agreement number 090-15-09032015) of the University of Leipzig, Germany. All participants provided written informed consent for the anonymized analysis of their data. We report all measures, manipulations, and exclusions in these studies, though no participants were excluded from the analysis.

\section{Procedures}

Participants were provided with a list of words and for each one, they were asked to rate in how far they felt "currently driven by these motivations, feelings or states," on a continuous visual analog scale ranging -350 to 350 (numbers were not visible to participants). These novel questionnaire items probed the seven motives of interest and were taken from the motive-specific words individuated in study 1, above. Specifically, the fear-related items were "apprehensive," "afraid," “timid," "nervous," "panic-stricken," "overcautious," "frightened," "reserved"; the anger-related items were "aggressive," "angry," “offended," "irritable," "argumentative," "tempestuous," "spirited," care-related items were "caring," "protective," "kind-hearted," "cordial," "helpful," "affectionate," "sympathetic," and "consoling"; power-related items were "mighty," "dominant," "authoritarian," "firm," "influential," "condescending," and "officious"; achievement items were "hard-working," "industrious," "capable," "efficient," “ambitious," “success-driven," “obstinate," “productive”; affiliation-related items were "entertaining," "ingratiating," "excluded," “conventional," “attached," “obliging," "popular"; and consumption items were "consumerist," "hoarding," "avaricious," "greedy," “materialistic," “cheap," “pleasureseeking," "acquisitive," “desire to buy," "gluttonous." In addition to these motive-related constructs, affect was measured by asking participants to provide ratings on a number of items related either to happiness ("content," "happy," "overjoyed," "pleasant," "enthusiastic") or sadness ("sad," "downcast"). Overall, the questionnaire consisted of 63 items. The order of the items was fully randomized for each participant, who viewed seven items per page.

\section{Analysis}

The ratings on items related to each motive displayed acceptable internal reliability: fear (Cronbach's $\alpha=0.87)$, anger $(\alpha=0.83)$, power $(\alpha=0.86)$, care $(\alpha=0.92)$, achievement $(\alpha=0.88)$, affiliation $(\alpha=0.67)$, consumption $(\alpha=0.84)$. We thus first ipsatized the ratings for each subject and then aggregated over the items related to each motive. This resulted in 7 motive-related and 2 affect-related measures, for each participant. As for study 1 , we then subjected these measures to principle component analysis, focusing on the seven motive-related measures as variables of interest and using the two affect measures as supplementary variables. As we aimed to establish whether the dimensions that explain the most variance at the semantic level (as investigated in study 1) also do so at the subjective level (as investigated here), we focused on the first two components of the PCA solution. 


\section{Results}

\section{Subjective-Experiential Closeness of Seven Motives}

Taken together, the first two components of a PCA solution explained $51.6 \%$ of the seven spontaneously occurring motives of interest, as measured by ratings on a visual analog scale (Figure 1, right). The first of the components (which explained $29.8 \%$ of the total variance) most clearly differentiated between fear, anger and consumption on the one hand (all scores $>0.56$ ) and achievement and care on the other (scores < -0.50). The second component (which explained $21.8 \%$ of total variance) differentiated between more clearly between care and affiliation on the one end (both scores $<-0.56$ ), and power and achievement on the other (scores $>0.35$ ). As for the supplementary variables, happiness and sadness were both (oppositely) related to the 1st dimension (with scores respectively $>0.54$ and $<-0.63$ ), with the exception of consumption, these dimensions clearly resembled those individuated in study 1, as can be observed in Figure $\mathbf{1}$ where, to facilitate comparability with the corresponding figure of study 1 (Figure 1, left), we plotted the 1st component (i.e., the component that explained the most variance) on the $y$-axis and the 2 nd on the $\mathrm{x}$-axis.

\section{DISCUSSION}

As a first step toward a motivation-based decision making framework that integrates psychology, neurobiology and behavioral economics, the main goal of the present paper was to investigate how seven relevant motives that have consistently recurred in one or all of these reviewed fields relate to one another, both on the semantic-conceptual as well as the subjective-experiential level. This preliminary set of motives are consumption/resource-seeking, care, affiliation, power-status, achievement, threat avoidance, and threat approach. The second goal of the present paper was to provide a word list of motives that could be used in future experimental studies on the influence of motives on economic decision making.

The analyses of a word-categorization task revealed that subjects coherently differentiated between the seven motives, as they agreed on which words were more related to one motive as compared to any of the others. In spite of this, participants disagreed more frequently on how to categorize words to some motives more than others. This enabled to obtain a spatial proxy of the relative conceptual overlap of each of the tested motives (Figure 1, left). The 1st dimension of the space differentiated between care, affiliation and fear on one side and power, achievement and consumption on the other. As anticipated, this separation is reminiscent of a communion/agency distinction (Bakan, 1966; Diehl et al., 2004; Abele et al., 2008), or a mastery/sympathy distinction (Apter, 1984; Apter et al., 1998), with care and affiliation words loading on one side, and power, achievement and consumption loading on the other. The 2 nd dimension was partially related to valence and especially differentiated threat approach, threat avoidance, and power, on the one side, from care, affiliation, achievement and consumption, on the other. These inter-relations amongst motives were not only apparent in the semantic but also in the subjective atlas.

In both atlases, we found that care and affiliation were conceptualized and experienced as close but were differentiated along a previously reported valence related gradient (Abele et al., 2008) within the communion side of the space: most of the negatively valenced communion-related words were in fact attributed to the affiliation motive (e.g., "conventional," "excluded," "attached/clingy," "ingratiating," "conformist" etc.), while all but one care-specific word had positive valence (i.e., "pampering," as opposed to "warm-hearted," "soft-hearted," "motherly," "kind," "understanding" etc.). In line with this, many positively valenced affiliation-specific words (e.g., "talkative," "affable," "gregarious," “communicative," “sociable") did not survive correction for multiple comparisons, suggesting that, as affiliation-related words become positive, they also become more "conflated" with care. These results suggest that care and affiliation are partially distinguished by valence. From a more conceptual perspective we speculate that the distinction between care and affiliation could also be related to the fact that nearly all care-specific words clearly denoted other-oriented motivation and behaviors, a motive to protect/help/accept others (e.g., “selfless," “generous," “sacrificing," “unselfish," "helpful," "protective" etc.) while those related to affiliation expressed a more self-focused need to be protected/helped/accepted or liked by others (e.g., "clingy," "popular," "attached"). This is in line with Apter's distinction between alloic vs. autic sympathy, and colleagues (1998), i.e., respectively, the motivation to nurture and love others vs. the need to be loved. Such a view is also compatible with the benevolence vs. conformity distinction in the quasi-circumplex model of Schwartz and Boehnke (2004), where benevolence is ascribed to the higher-order construct of "selftranscendence"- values which "promote the welfare of others, close and distant, and of nature" (p. 236)-while conformity is ascribed to the higher-order construct of "conservation"-values which "preserve the status quo and the certainty it provides (security, conformity, tradition)" (see Schwartz and Boehnke, 2004, p. 236). Notably, Schwartz and colleagues find that, despite this important distinction, conformity (i.e., affiliation in our model) and benevolence (i.e., care) are relatively proximal, as our data also suggests, despite noticeable methodological differences.

We also found that affiliation is semantically conceptualized and subjectively experienced as closer to threat avoidance (or fear) than care. Previous literature has frequently linked affiliation to various negatively valenced states of social anxiety, social exclusion or separation distress (Eisenberger et al., 2003; Eisenberger, 2012). Moreover, a separate line of studies on empathy for pain and altruistic behavior have shown that when distress prevails over empathic concern, subjects tend to make more self-protective and avoidant choices rather than altruistic ones (Batson et al., 1983, 1987; Singer and Klimecki, 2014). Our second finding could thus further qualify with our first one: affiliation-related concepts may be more negatively valenced than care-related concepts, partly because the motive of affiliation seems connected to the fear of separation and not belonging, and thus being more closely connected to the motive of fear. Similarly, in Schwartz and Boehnke's (2004) multi-dimensional 
model of values (Schwartz and Boehnke, 2004), security and conformity (analogs to our threat-avoidance and affiliation motives) are immediate neighbors, and both belong to the higherorder value of Conservation. In line with this, benevolence (similar to our care motive) is more distant from security values than conformity.

Moreover, and again similarly to Schwartz and Boehnke (2004), we found that power-status and achievement-related motives were also relatively close (as well as antagonistic to care and affiliation). Indeed, Schwartz and Boehnke (2004) propose that one higher-order value, self-enhancement ["to enhance (...) own personal interests even at the expense of others," p. 236], combines power and achievement [and forms "a bipolar dimension with the higher-order type called selftranscendence, that combines universalism and benevolence values." (p. 236)]. In line with this, power and achievement have also been previously indirectly associated with agency (Bakan, 1966; Diehl et al., 2004; Abele et al., 2008), which has been suggested to span from positive aspects of agency (such as "independence" and "achievement"), to more "excessive" forms of agency, such as "hunger for power and superiority," culminating "in aggressive or rude behavior" (Bakan, 1966; Diehl et al., 2004; Abele et al., 2008). This agency spectrum appeared to be reflected in our motivational space as well, with power/status-related words (e.g., "influential," "dominant," "mighty," "despotic" etc.) standing vertically between those related to more positively valenced achievement ("determined," "success-driven," "ambitious," "motivated," "capable," "efficient," "competitive" etc.) and those related to anger ("aggressive," "hateful," "hostile," "argumentative" etc.). With regard to the content of the two sets of words, it also appears that achievementspecific words are more related to performance and seem only "incidentally" social. For instance, among the achievementspecific words, only the word "competitive" appears to imply some social comparison, while most power-related words more explicitly refer to dominance over others. Schematically, achievement could be conceptualized as socially neutral, or asocial, while power appears more frequently anti-social (van Honk et al., 2016).

Our fourth hypothesis, also substantiated in the results, was that threat approach and threat avoidance would be conceptually close to one another. The proximity of these two motives is in line with the notion that they can be considered as two opposing response tendencies (approach vs. avoidance) to perceived threats (Carver and Harmon-Jones, 2009). Indeed, anger and fear-related states are generally both low in valence and high in arousal, they are frequently experienced together (Moons et al., 2010), and they have been frequently found to cluster together in previous word sorting tasks (Russell, 1980; Posner et al., 2005; Kuppens et al., 2013). Interestingly, even though threat avoidance and threat approach both stem from an over-arching threat system and may thus be characterized as two sides of one coin, they can still be distinguished on the level of behavior, affective states, physiological arousal and underlying activation patterns (Stemmler, 2004; Stemmler et al., 2007). In line with this, we find that threat approach and avoidance display close spatial proximity, but are nonetheless distinct.
The multi-dimensional model of human values (Schwartz and Boehnke, 2004) does not entail a motive or value similar to threat approach. However, in the motivational style profile (Apter et al., 1998), "negativism" (associated with acting provocatively and/or reacting angrily to situations) is treated as part of the metamotivational oppositional modes of negativism vs. conformity. Such an opposition implies that the respective motivational modes are inherently antagonistic. Similarly, we find large spatial distance between anger and affiliation (see Figure 1).

The only aspect on which the semantic and subjective atlases diverged was with regard to our more exploratory consumption motive. In both atlases, consumption was related to our alleged "agency" dimension, however, in the semantic atlas, consumption overlapped highly with achievement and less with power, while in the subjective atlas it shifted away from achievement, and toward threat approach/anger. Though unanticipated, we speculate that this difference could be due to the fact that consumptionoriented behaviors are frequently conceptualized as linked to achievement (or perhaps even rationalized in the name of achievement). Similarly, in the theoretical model of relations among 10 motivational types of values (Schwartz and Boehnke, 2004), hedonism, which comes close to the consumption motive suggested here, can be found in close neighborhood to achievement. This proximity is in line with the notion that self-interested maximization of profit or money is frequently conceived as "an indicator of achievement, respect, and freedom or power" (Lea and Webley, 2006, p. 170). However, at the level of experience, it has also been suggested that the pursuit of profit (i.e., consumption) can be used as a socially acceptable or ritualized tool to express aggressive instincts (Behrendt, 2006), and that anger can be a "hidden motivator" behind the desire to buy products (Veling et al., 2011). Our finding that anger and consumption are subjectively experienced but not semantically conceptualized as close are in line with this notion, that anger and consumption may share a subconscious link (Behrendt, 2006; Veling et al., 2011). Furthermore, in the quasi-circumplex model of the 10 motivational types of values (Schwartz and Boehnke, 2004), hedonism is situated opposed to benevolence. Similarly, we find that care and consumption are spatially located on the opposite sides of the atlases.

One question our pattern of results may raise is that much literature has found communion and agency to be independent dimensions rather than negatively related dimensions (e.g., Abele et al., 2008). However, anti-correlated agency and communion dimensions have also been reported. For example, Abele et al. (2008) observe such an anti-correlation and suggest this may be due to the fact that they chose words in order to maximize the "separation" of the constructs of interest (agency and communion in their case). This also applies to our studies, and to study 2 in particular, given that the words chosen for the subjective-experiential ratings were those that maximally differentiated between motives in the categorization task (i.e., participants were likely to assign those words to one motivational category more than any other). Moreover, as again suggested by Abele and colleagues, "the finding that agency and communion are negatively related if valence is controlled for is in line with previous research" (p. 1214, cursive 
ours). Our valence-related PCA dimension might have captured valence-related variance, thus partially allowing such a negative correlation of agency and communion-related motives to surface. Finally, it should also be noted that, even though not prominent in the agency/communion literature, the antagonistic nature of care/affiliation vs. power/achievement is more central in the model of human values presented by Schwartz and Boehnke. Here in fact, the closest value correspondents of these motives (namely benevelonce/conformity vs. power/achievement) are assigned to opposite ends of an explicitly bipolar higher-order value construct, which separates between "Self-enhancement" (the motivation to enhance own personal interests, even at the expense of other) and "Self-transcendence" (the motivation to promote the welfare of others, close and distant, and of nature). Overall, this suggests that the negative relation of agency and communion-related motives can be reconciled with previous findings.

Finally, our sorting task also enabled to provide a list of 213 motive-specific words (Supplementary Table 1). Many of these words corroborate existing questionnaire items related to achievement, power, fear, anger and what we refer to as care (Lefcourt, 1991; Buss and Perry, 1992; Costa and McCrae, 1992; Lachman and Weaver, 1998; Abele et al., 2008; Spielberger's State, 2010). In addition, our findings also suggest that some words that have often been used in the literature may not be optimal to disambiguate between certain motives. For instance, the words "cordial" or "likable" are related to "warmth" in the NEO-PIR but also to affiliation tendency by Mehrabian's scale of Affiliative Tendency (Mehrabian, 1994). Our results indicate that, when confronted with the choice, participants indeed might associate these words with care rather than with affiliation. Researchers juxtaposing self-report measures to (economic) decision making paradigms (Maner et al., 2002; Bosman et al., 2005; Ben-Shakhar et al., 2007; Reuben and van Winden, 2008; Hopfensitz and Reuben, 2009; Eimontaite et al., 2013) could use our motivespecific words to better identify the motives underlying specific decisions and investigate whether indeed such motives are related to the corresponding decision patterns anticipated above (Table 1). In fact, recent studies have already adopted a subset of the motive specific words obtained here and found that they can be simultaneously sensitive to corresponding motivational inductions (e.g., of care, power, fear, or anger) and predictive of economic behaviors of interest (Chierchia et al., 2017, 2021; Bartke et al., 2019).

Future studies could use some of these words using spatial arrangement methods (Richie et al., 2020), in which no preexisting categories are given and participants freely arrange words on a screen, based on their perceived similarities (such that words that are spatially closer are perceived to be more similar). This would allow to compute semantic distances based on a continuous measure rather than a categorical one. It would also allow investigating whether our results hold-that is, whether similar dimensions would differentiate between motives-when no over-arching categories are provided at all. This would provide further support to the notion that, much as in an atlas, there could be a useful underlying coordinate system to help navigate between important motives in economics, biology and psychology: a dimension that distinguishes between agency and communion on one side, and a positive and negative affect on the other.

\section{CONCLUSION}

Integrating literature from motivation psychology, neurobiology and behavioral economics, we propose that at least seven distinct motives are likely to be crucial driving forces of human decision making: "consumption/resource seeking," "care," "affiliation," "achievement," "status-power," "threat approach," and "threat avoidance." As a first preliminary investigation of such a motivational taxonomy, we analyzed how participants differentiate between these seven motives, and how such motives are inter-related on a semantic-conceptual as well as subjectiveexperiential level. We find that whereas care and affiliation are close, affiliation is closer to threat avoidance (or fear) and could thus refer to a more self-centered need to belong and to fear of social exclusion, whereas care is more positively valenced and could denote more altruistic orientation. On the other side of both semantic and experiential atlases, we find achievement overlapping highly with power, but with power lying closer to threat approach (or anger). Together with these atlases, we also provide a database of motive-specific words to be used in future research linking motives to decision making. Overall, we prospect a decision making model that goes beyond approach and avoidance, that is psycho-biologically plausible, and that highlights the importance of contexts in modulating motivation (e.g., Bosworth et al., 2016). Such a model could justify policies focusing on how institutions, contexts and frames can affect motives, and possibly harness them to bolster cooperation.

\section{DATA AVAILABILITY STATEMENT}

The raw data supporting the conclusions of this article will be made available by the authors, without undue reservation.

\section{ETHICS STATEMENT}

The studies involving human participants were reviewed and approved by the local ethics committee of the Medical Faculty of the University of Leipzig (n. 090-15-090032015). The participants provided their written informed consent to participate in this study.

\section{AUTHOR CONTRIBUTIONS}

TS and DS conceived the study and together with GC and FPL, designed the study. MP provided the theoretical backbone by carrying out a comprehensive literature review on motivation psychology and biology and SB on economic theory. FPL and GC coordinated the empirical studies, collected the data, and carried out the statistical analyses. All authors hefcrm-07626975 - Crx2lped draft the manuscript and gave final approval for publication. 


\section{FUNDING}

The support of the Institute for New Economic Thinking to the authors (INET-Grant ID \#INO13-00036) is gratefully acknowledged.

\section{ACKNOWLEDGMENTS}

We thank Simon Bartke for remarks on earlier drafts of this manuscript, and Yvonne Melzer for her literature research

\section{REFERENCES}

Abele, A. E., Uchronski, M., Suitner, C., and Wojciszke, B. (2008). Towards an operationalization of the fundamental dimensions of agency and communion: trait content ratings in five countries considering valence and frequency of word occurrence. Eur. J. Soc. Psychol. 38, 1202-1217. doi: 10.1002/ejsp.575

Adolphs, R. (2013). The biology of fear. Curr. Biol. 23, R79-R93. doi: 10.1016/j.cub.2012.11.055

Akerlof, G. A., and Kranton, R. E. (2000). Economics and identity. Q. J. Econ. 115, 715-753. doi: $10.1162 / 003355300554881$

Alcaro, A., Huber, R., and Panksepp, J. (2007). Behavioral functions of the mesolimbic dopaminergic system: an affective neuroethological perspective. Brain Res. Rev. 56, 283-321. doi: 10.1016/j.brainresrev.2007.07.014

Alcaro, A., and Panksepp, J. (2011). The SEEKING mind: primal neuroaffective substrates for appetitive incentive states and their pathological dynamics in addictions and depression. Neurosci. Biobehav. Rev. 35, 1805-1820. doi: 10.1016/j.neubiorev.2011.03.002

Anderson, C., and Galinsky, A. D. (2006). Power, optimism, and risk-taking. Eur. J. Soc. Psychol. 36, 511-536. doi: 10.1002/ejsp.324

Andrade, E. B., and Ariely, D. (2009). The enduring impact of transient emotions on decision making. Organ. Behav. Hum. Decis. Process. 109, 1-8. doi: 10.1016/j.obhdp.2009.02.003

Andreoni, J. (1990). Impure altruism and donations to public goods: a theory of warm-glow giving. Econ. J. 100:464. doi: 10.2307/2234133

Apicella, C. L., Carré, J. M., and Dreber, A. (2015). Testosterone and economic risk taking: a review. Adapt. Hum. Behav. Physiol. 1, 358-385. doi: 10.1007/s40750-014-0020-2

Apter, M. J. (1984). Reversal theory and personality: a review. J. Res. Pers. 18, 265-288. doi: 10.1016/0092-6566(84)90013-8

Apter, M. J., Mallows, R., and Williams, S. (1998). The development of the motivational style profile. Pers. Individ. Dif. 24, 7-18. doi: 10.1016/S0191-8869(97)00148-7

Atkinson, J. W. (1964). An Introduction to Motivation. Oxford: Van Nostrand.

Atkinson, J. W., and Feather, N. T. (1966). A Theory of Achievement Motivation, Vol. 66. New York, NY: Wiley New York.

Bakan, D. (1966). The Duality of Human Existence: An Essay on Psychology and Religion. Oxford: Rand Mcnally.

Bakermans-Kranenburg, M. J., and van Ijzendoorn, M. H. (2013). Sniffing around oxytocin: review and meta-analyses of trials in healthy and clinical groups with implications for pharmacotherapy. Transl. Psychiatry 3:e258. doi: $10.1038 /$ tp.2013.34

Balliet, D., Wu, J., and De Dreu, C. K. (2014). Ingroup favoritism in cooperation: a meta-analysis. Psychol. Bull. 140:1556. doi: 10.1037/a0037737

Barrett, L. F. (2004). Feelings or Words? Understanding the content in selfreport ratings of experienced emotion. J. Pers. Soc. Psychol. 87, 266-281. doi: 10.1037/0022-3514.87.2.266

Barrett, L. F., and Russell, J. A. (2014). The Psychological Construction of Emotion. New York, NY: Guilford Publications.

Bartels, A., and Zeki, S. (2004). The neural correlates of maternal and romantic love. Neuroimage 21, 1155-1166. doi: 10.1016/j.neuroimage.2003.11.003

Bartke, S., Bosworth, S. J., Snower, D. J., and Chierchia, G. (2019). Motives and comprehension in a public goods game with induced emotions. Theory Decis. 86, 205-238. doi: 10.1007/s11238-018-9677-5 during early stages of this paper, especially regarding the biological review.

\section{SUPPLEMENTARY MATERIAL}

The Supplementary Material for this article can be found online at: https://www.frontiersin.org/articles/10.3389/fpsyg. 2020.568064/full\#supplementary-material

Batson, C. D., and Ahmad, N. (2001). Empathy-induced altruism in a prisoner's dilemma II: what if the target of empathy has defected? Eur. J. Soc. Psychol. 31, 25-36. doi: 10.1002/ejsp.26

Batson, C. D., Fultz, J., and Schoenrade, P. A. (1987). Distress and empathy: two qualitatively distinct vicarious emotions with different motivational consequences. J. Pers. 55, 19-39. doi: 10.1111/j.1467-6494.1987.tb 00426.x

Batson, C. D., and Moran, T. (1999). Empathy-induced altruism in a prisoner's dilemma. Eur. J. Soc. Psychol. 29, 909-924.

Batson, C. D., O'Quin, K., Fultz, J., Vanderplas, M., and Isen, A. M. (1983). Influence of self-reported distress and empathy on egoistic versus altruistic motivation to help. J. Pers. Soc. Psychol. 45, 706-718. doi: 10.1037/0022-3514.45.3.706

Baumeister, R. F., and Leary, M. R. (1995). The need to belong: desire for interpersonal attachments as a fundamental human motivation. Psychol. Bull. 117, 497-529. doi: 10.1037/0033-2909.117.3.497

Baumgartner, T., Heinrichs, M., Vonlanthen, A., Fischbacher, U., and Fehr, E. (2008). Oxytocin shapes the neural circuitry of trust and trust adaptation in humans. Neuron 58, 639-650. doi: 10.1016/j.neuron.2008. 04.009

Becker, G. S. (1974). A Theory of Social Interactions. J. Political Econ. 82, 1063-1093. doi: 10.1086/260265

Behrendt, R.-P. (2006). The desire to obtain money: a culturally ritualised expression of the aggressive instinct. Behav. Brain Sci. 29, 178-179. doi: 10.1017/S0140525X06259041

Ben-Shakhar, G., Bornstein, G., Hopfensitz, A., and van Winden, F. (2007). Reciprocity and emotions in bargaining using physiological and selfreport measures. J. Econ. Psychol. 28, 314-323. doi: 10.1016/j.joep.2007. 02.005

Bernhard, H., Fehr, E., and Fischbacher, U. (2006). Group affiliation and altruistic norm enforcement. Am. Econ. Rev. 96, 217-221. doi: 10.1257/000282806777212594

Berridge, K. C., Ho, C.-Y., Richard, J. M., and DiFeliceantonio, A. G. (2010). The tempted brain eats: pleasure and desire circuits in obesity and eating disorders. Brain Res. 1350, 43-64. doi: 10.1016/j.brainres.2010.04.003

Berridge, K. C., and Robinson, T. E. (1998). What is the role of dopamine in reward: hedonic impact, reward learning, or incentive salience? Brain Res. Rev. 28, 309-369. doi: 10.1016/S0165-0173(98)00019-8

Bird, B. M., Geniole, S. N., Procyshyn, T. L., Ortiz, T. L., Carré, J. M., and Watson, N. V. (2019). Effect of exogenous testosterone on cooperation depends on personality and time pressure. Neuropsychopharmacology 44:538. doi: 10.1038/s41386-018-0220-8

Böckler, A., Tusche, A., and Singer, T. (2016). The structure of human prosociality: differentiating altruistically motivated, norm motivated, strategically motivated, and self-reported prosocial behavior. Soc. Psychol. Pers. Sci. 7, 530-541. doi: 10.1177/1948550616639650

Boksem, M. A. S., Mehta, P. H., Van den Bergh, B., van Son, V., Trautmann, S. T., Roelofs, K., et al. (2013). Testosterone inhibits trust but promotes reciprocity. Psychol. Sci. 24, 2306-2314. doi: 10.1177/09567976134 95063

Bond, A. J., and Wingrove, J. (2010). "The neurochemistry and psychopharmacology of anger," in International Handbook of Anger, eds M. Potegal, G. Stemmler, and C. Spielberger (New York, NY: Springer), 79-102. 
Bornemann, B., Kok, B. E., Böckler, A., and Singer, T. (2016). Helping from the heart: voluntary upregulation of heart rate variability predicts altruistic behavior. Biol. Psychol. 119, 54-63. doi: 10.1016/j.biopsycho.2016.07.004

Bos, P. A., Hermans, E. J., Ramsey, N. F., and van Honk, J. (2012). The neural mechanisms by which testosterone acts on interpersonal trust. Neuroimage 61, 730-737. doi: 10.1016/j.neuroimage.2012.04.002

Bosman, R., Sutter, M., and van Winden, F. (2005). The impact of real effort and emotions in the power-to-take game. J. Econ. Psychol. 26, 407-429. doi: 10.1016/j.joep.2004.12.005

Bosworth, S. J., Singer, T., and Snower, D. J. (2016). Cooperation, motivation and social balance. J. Econ. Behav. Organ. 126, 72-94. doi: 10.1016/j.jebo.2015.12.005

Bradley, M. M., and Lang, P. J. (1999). Affective Norms for English Words (ANEW): Instruction Manual and Affective Ratings (Vol. 30, No. 1, pp. 25-36). Technical Report C-1, the Center for Research in Psychophysiology, University of Florida.

Bromberg-Martin, E. S., Matsumoto, M., and Hikosaka, O. (2010). Dopamine in motivational control: rewarding, aversive, and alerting. Neuron 68, 815-834. doi: 10.1016/j.neuron.2010.11.022

Bruce, N., and Waldman, M. (1990). The Rotten-Kid theorem meets the Samaritan's dilemma. Q. J. Econ. 105:155. doi: 10.2307/2937823

Burnham, T. C. (2007). High-testosterone men reject low ultimatum game offers. Proc. R. Soc. B Biol. Sci. 274, 2327-2330. doi: 10.1098/rspb.2007.0546

Buss, A. H., and Perry, M. (1992). The aggression questionnaire. J. Pers. Soc. Psychol. 63, 452-459. doi: 10.1037/0022-3514.63.3.452

Camerer, C. F. (2003). Behavioral Game Theory: Experiments in Strategic Interaction. Princeton, NJ: Princeton University Press.

Camille, N., Coricelli, G., Sallet, J., Pradat-Diehl, P., Duhamel, J. R., and Sirigu, A. (2004). The involvement of the orbitofrontal cortex in the experience of regret. Science 304, 1167-1170. doi: 10.1126/science. 1094550

Canessa, N., Crespi, C., Motterlini, M., Baud-Bovy, G., Chierchia, G., Pantaleo, G., et al. (2013). The functional and structural neural basis of individual differences in loss aversion. J. Neurosci. 33, 14307-14317. doi: 10.1523/JNEUROSCI.0497-13.2013

Carpenter, J., and Matthews, P. H. (2009). What norms trigger punishment? Exp. Econ. 12, 272-288. doi: 10.1007/s10683-009-9214-z

Carré, J. M., and Archer, J. (2018). Testosterone and human behavior: the role of individual and contextual variables. Curr. Opin. Psychol. 19, 149-153. doi: 10.1016/j.copsyc.2017.03.021

Carter, C. S. (1998). Neuroendocrine perspectives on social attachment and love. Psychoneuroendocrinology 23, 779-818. doi: 10.1016/S0306-4530(98)00055-9

Carver, C. S., and Harmon-Jones, E. (2009). Anger is an approach-related affect: evidence and implications. Psychol. Bull. 135, 183-204. doi: 10.1037/a0013965

Charness, G., Naef, M., and Sontuoso, A. (2019). Opportunistic conformism. J. Econ. Theory 180, 100-134. doi: 10.1016/j.jet.2018.12.003

Chein, J., Albert, D., O’Brien, L., Uckert, K., and Steinberg, L. (2011). Peers increase adolescent risk taking by enhancing activity in the brain's reward circuitry. Dev. Sci. 14, F1-F10. doi: 10.1111/j.1467-7687.2010.01035.x

Chierchia, G., Lesemann, F. H. P., Snower, D., Vogel, M., and Singer, T. (2017). Caring cooperators and powerful punishers: differential effects of induced care and power motivation on different types of economic decision making. Sci. Rep. 7:11068. doi: 10.1038/s41598-017-11580-8

Chierchia, G., Lesemann, F. P., Snower, D., and Singer, T. (2021). Cooperation across multiple game-theoretical paradigms is increased by fear more than anger in selfish individuals. PsyArXiv. doi: 10.31234/osf.io/h49u7

Cole, H. L., Mailath, G. J., and Postlewaite, A. (1992). Social norms, savings behavior, and growth. J. Polit. Econ. 100, 1092-1125. doi: 10.1086/261855

Condon, P., and Feldman Barrett, L. (2013). Conceptualizing and experiencing compassion. Emotion 13, 817-821. doi: 10.1037/a0033747

Costa, P. T., and McCrae, R. R. (1992). Revised NEO Personality Inventory (NEO PI-R) and NEO Five Factor Inventory: Professional Manual. Odessa, FL: Psychological Assessment Resources.

Cuddy, A. J. C., Fiske, S. T., and Glick, P. (2008). Warmth and competence as universal dimensions of social perception: the stereotype content model and the BIAS map. Adv. Exp. Social Psychol. 40, 61-149. doi: 10.1016/S0065-2601(07)00002-0

Dawes, R. M. (1980). Social dilemmas. Annu. Rev. Psychol. 31, 169-193. doi: 10.1146/annurev.ps.31.020180.001125
Dayan, P., and Balleine, B. W. (2002). Reward, motivation, and reinforcement learning. Neuron 36, 285-298. doi: 10.1016/S0896-6273(02)00963-7

Dayan, P., and Berridge, K. C. (2014). Model-based and model-free Pavlovian reward learning: revaluation, revision, and revelation. Cogn. Affect. Behav. Neurosci. 14, 473-492. doi: 10.3758/s13415-014-0277-8

de Martino, B., Camerer, C. F., and Adolphs, R. (2010). Amygdala damage eliminates monetary loss aversion. Proc. Natl. Acad. Sci. U.S.A. 107, 3788-3792. doi: 10.1073/pnas.0910230107

de Waal, F. (2007). Chimpanzee Politics: Power and Sex Among Apes. Baltimore, MD: Johns Hopkins University Press.

Deci, E. L., and Moller, A. C. (2005). "The concept of competence: a starting place for understanding intrinsic motivation and self-determined extrinsic motivation," in Handbook of Competence and Motivation: Theory and Application, eds A. J. Elliot, C. S. Dweck, and D. S. Yeager (New York, NY: Plenum Press), 579-597.

Delgado, M. R., Gillis, M. M., and Phelps, E. A. (2008). Regulating the expectation of reward via cognitive strategies. Nat. Neurosci. 11, 880-881. doi: $10.1038 / \mathrm{nn} .2141$

Depue, R. A., and Collins, P. F. (1999). Neurobiology of the structure of personality: dopamine, facilitation of incentive motivation, and extraversion. Behav. Brain Sci. 22, 491-517. doi: 10.1017/S0140525X99002046

Diehl, M., Owen, S. K., and Youngblade, L. M. (2004). Agency and communion attributes in adults' spontaneous self-representations. Int. J. Behav. Dev. 28, 1-15. doi: 10.1080/01650250344000226

Dimant, E. (2019). Contagion of pro-and anti-social behavior among peers and the role of social proximity. J. Econ. Psychol. 73, 66-88. doi: 10.1016/j.joep.2019.04.009

Dreher, J. C., Dunne, S., Pazderska, A., Frodl, T., Nolan, J. J., and O’Doherty, J. P. (2016). Testosterone causes both prosocial and antisocial status-enhancing behaviors in human males. Proc. Natl. Acad. Sci. U.S.A. 113, 11633-11638. doi: $10.1073 /$ pnas. 1608085113

Dunn, J. R., and Schweitzer, M. E. (2005). Feeling and believing: the influence of emotion on trust. J. Pers. Soc. Psychol. 88:736. doi: 10.1037/0022-3514.88.5.736

Eimontaite, I., Nicolle, A., Schindler, I., and Goel, V. (2013). The effect of partnerdirected emotion in social exchange decision-making. Front. Psychol. 4:469. doi: 10.3389/fpsyg.2013.00469

Eisenberger, N. I. (2012). The pain of social disconnection: examining the shared neural underpinnings of physical and social pain. Nat. Rev. Neurosci. 13, 421-434. doi: 10.1038/nrn3231

Eisenberger, N. I., Lieberman, M. D., and Williams, K. D. (2003). Does rejection hurt? An fMRI study of social exclusion. Science 302, 290-292. doi: $10.1126 /$ science. 1089134

Eisenegger, C., Haushofer, J., and Fehr, E. (2011). The role of testosterone in social interaction. Trends Cogn. Sci. 15, 263-271. doi: 10.1016/j.tics.2011.04.008

Eisenegger, C., Naef, M., Snozzi, R., Heinrichs, M., and Fehr, E. (2010). Prejudice and truth about the effect of testosterone on human bargaining behaviour. Nature 463, 356-359. doi: 10.1038/nature08711

Ekström, M. (2012). Do watching eyes affect charitable giving? Evidence from a field experiment. Exp. Econ. 15, 530-546. doi: 10.1007/s10683-011-9312-6

Emmons, R. A., and McAdams, D. P. (1991). Personal strivings and motive dispositions: exploring the links. Pers. Soc. Psychol. Bull. 17, 648-654. doi: $10.1177 / 0146167291176007$

Engen, H. G., and Singer, T. (2015). Compassion-based emotion regulation upregulates experienced positive affect and associated neural networks. Soc. Cogn. Affect. Neurosci. 10, 1291-1301. doi: 10.1093/scan/nsv008

Epstein, S. (1972). The nature of anxiety with emphasis upon its relationship to expectancy. Anxiety Curr. Trends Theory Res. 2, 291-337. doi: 10.1016/B978-0-12-657402-9.50007-7

Fehr, E., and Fischbacher, U. (2003). The nature of human altruism. Nature 425, 785-791. doi: 10.1038/nature02043

Fehr, E., and Fischbacher, U. (2004). Third-party punishment and social norms. Evol. Hum. Behav. 25, 63-87. doi: 10.1016/S1090-5138(04)00005-4

Fehr, E., Herz, H., and Wilkening, T. (2013). The lure of authority: motivation and incentive effects of power. Am. Econ. Rev. 103, 1325-1359. doi: 10.1257/aer.103.4.1325

Fehr, E., and Schurtenberger, I. (2018). Normative foundations of human cooperation. Nat. Hum. Behav. 2:458. doi: 10.1038/s41562-018-0385-5 
Feldman, R. (2012). Oxytocin and social affiliation in humans. Horm. Behav. 61, 380-391. doi: 10.1016/j.yhbeh.2012.01.008

Ferrer, R. A., Alexander, M., Paul, M. L., and Jennifer, S. L. (2017). Revisiting the effects of anger on risk-taking: empirical and meta-analytic evidence for differences between males and females. J. Behav. Decis. Mak. 30, 516-526. doi: 10.1002/bdm.1971

Fessler, D. M. T., Pillsworth, E. G., and Flamson, T. J. (2004). Angry men and disgusted women: an evolutionary approach to the influence of emotions on risk taking. Organ. Behav. Hum. Decis. Process. 95, 107-123. doi: 10.1016/j.obhdp.2004.06.006

Fiske, S. T., Cuddy, A. J. C., and Glick, P. (2007). Universal dimensions of social cognition: warmth and competence. Trends Cogn. Sci. 11, 77-83. doi: 10.1016/j.tics.2006.11.005

Fodor, E. M., and Riordan, J. M. (1995). Leader power motive and group conflict as influences on leader behavior and group member self-affect. J. Res. Pers. 29, 418-431. doi: 10.1006/jrpe.1995.1024

Frank, R. (1985). The demand for unobservable and other nonpositional goods. Am. Econ. Rev. 75, 101-116.

Frank, R. H. (1988). Passions Within Reason: The Strategic Role of the Emotions. New York, NY, W W Norton and Co.

Gilboa, I., and Schmeidler, D. (2001). A Theory of Case-Based Decisions. Cambridge: Cambridge University Press.

Glimcher, P., Camerer, C., Fehr, E., and Poldrack, R. A. (2013). Neuroeconomics: Decision Making and the Brain. New York, NY: Academic Press.

Gómez-Miñambres, J. (2012). Motivation through goal setting. J. Econ. Psychol. 33, 1223-1239. doi: 10.1016/j.joep.2012.08.010

Gordon, D. S., and Lea, S. E. (2016). Who punishes? The status of the punishers affects the perceived success of, and indirect benefits from, "moralistic" punishment. Evol. Psychol. 14:1474704916658042. doi: $10.1177 / 1474704916658042$

Gordon, I., Martin, C., Feldman, R., and Leckman, J. F. (2011). Oxytocin and social motivation. Dev. Cogn. Neurosci. 1, 471-493. doi: 10.1016/j.den.2011. 07.007

Guinote, A., Cotzia, I., Sandhu, S., and Siwa, P. (2015). Social status modulates prosocial behavior and egalitarianism in preschool children and adults. Proc. Natl. Acad. Sci. U.S.A. 112, 731-736. doi: 10.1073/pnas.1414550112

Gummerum, M., Van Dillen, L. F., Van Dijk, E., and López-Pérez, B. (2016). Costly third-party interventions: the role of incidental anger and attention focus in punishment of the perpetrator and compensation of the victim. J. Exp. Soc. Psychol. 65, 94-104. doi: 10.1016/j.jesp.2016.04.004

Hall, J. L., Stanton, S. J., and Schultheiss, O. C. (2010). "Biopsychological and neural processes of implicit motivation," in Implicit Motives, eds O. C. Schultheiss and J. C. Brunstein (Oxford: Oxford University Press), 279-307.

Hamilton, W. D. (1964). The genetical evolution of social behaviour. I. J. Theoret. Biol. 7, 1-16. doi: 10.1016/0022-5193(64)90038-4

Harbaugh, W. T., Mayr, U., and Burghart, D. R. (2007). Neural responses to taxation and voluntary giving reveal motives for charitable donations. Science 316, 1622-1625. doi: 10.1126/science.1140738

Hardy, C. L., and Van Vugt, M. (2006). Nice guys finish first: the competitive altruism hypothesis. Pers. Social Psychol. Bull. 32, 1402-1413. doi: $10.1177 / 0146167206291006$

Hartley, C. A., and Phelps, E. A. (2012). Anxiety and decision-making. Biol. Psychiatry 72, 113-118. doi: 10.1016/j.biopsych.2011.12.027

Heckhausen, H. (1989). Motivation und Handeln. Berlin: Springer.

Heckhausen, J. (2000). Evolutionary perspectives on human motivation. Am. Behav. Sci. 43, 1015-1029. doi: 10.1177/00027640021955739

Heckhausen, J., and Heckhausen, H. (2010). "Motivation und entwicklung," in Motivation und Handeln, eds J. Heckhausen and H. Heckhausen (Berlin; Heidelberg: Springer), 427-488.

Hildebrandt, L. K., McCall, C., and Singer, T. (2017). Differential effects of attention-, compassion-, and socio-cognitively based mental practices on self-reports of mindfulness and compassion. Mindfulness 8, 1488-1512. doi: 10.1007/s12671-017-0716-z

Hoffman, E., McCabe, K., and Smith, V. L. (1996). Social distance and otherregarding behavior in dictator games. Am. Econ. Rev. 86, 653-660.

Hopfensitz, A., and Reuben, E. (2009). The importance of emotions for the effectiveness of social punishment. Econ. J. 119, 1534-1559. doi: $10.1111 / j .1468-0297.2009 .02288 . x$
Hull, C. L. (1943). Principles of Behavior: An Introduction to Behavior Theory. Oxford: Appleton-Century.

Ikemoto, S., and Panksepp, J. (1999). The role of nucleus accumbens dopamine in motivated behavior: a unifying interpretation with special reference to reward-seeking. Brain Res. Rev. 31, 6-41. doi: 10.1016/S0165-0173(99) 00023-5

Insel, T. R., and Young, L. J. (2001). The neurobiology of attachment. Nat. Rev. Neurosci. 2, 129-136. doi: 10.1038/35053579

Izuma, K., and Adolphs, R. (2013). Social manipulation of preference in the human brain. Neuron 78, 563-573. doi: 10.1016/j.neuron.2013.03.023

Jackson, D. N. (1974). Manual for the Personality Research Form. Goshen, NY: Research Psychologists Press.

Joshi, P. D., and Fast, N. J. (2013). Power and reduced temporal discounting. Psychol. Sci. 24, 432-438. doi: 10.1177/0956797612457950

Kahneman, D., and Tversky, A. (1979). Prospect theory: an analysis of decision under risk. Econometrica 47, 263-291. doi: 10.2307/1914185

Kanske, P., and Kotz, S. A. (2010). Leipzig affective norms for german: a reliability study. Behav. Res. Methods 42, 987-991. doi: 10.3758/BRM.42.4.987

Kasser, T. (2006). "Materialism and its alternatives," in A Life Worth Living: Contributions to Positive Psychology, eds M. Csikszentmihalyi and I. Csikszentmihalyi (New York, NY: Oxford University Press), 200-214.

Kasser, T., Rosenblum, K. L., Sameroff, A. J., Deci, E. L., Niemiec, C. P., Ryan, R. M., et al. (2014). Changes in materialism, changes in psychological well-being: evidence from three longitudinal studies and an intervention experiment. Motiv. Emot. 38, 1-22. doi: 10.1007/s11031-013-9371-4

Kirk, U., Gu, X., Sharp, C., Hula, A., Fonagy, P., and Montague, P. R. (2016). Mindfulness training increases cooperative decision making in economic exchanges: evidence from fMRI. Neuroimage 138, 274-283. doi: 10.1016/j.neuroimage.2016.05.075

Klimecki, O. M., Leiberg, S., Lamm, C., and Singer, T. (2012). Functional neural plasticity and associated changes in positive affect after compassion training. Cereb. Cortex 23, 1552-1561. doi: 10.1093/cercor/bhs 142

Klimecki, O. M., Leiberg, S., Ricard, M., and Singer, T. (2014). Differential pattern of functional brain plasticity after compassion and empathy training. Soc. Cogn. Affect. Neurosci. 9, 873-879. doi: 10.1093/scan/nst060

Klucharev, V., Hytönen, K., Rijpkema, M., Smidts, A., and Fernández, G. (2009). Reinforcement learning signal predicts social conformity. Neuron 61, 140-151. doi: 10.1016/j.neuron.2008.11.027

Kollock, P. (1998). Social dilemmas: the anatomy of cooperation. Annu. Rev. Sociol. 24, 183-214. doi: 10.1146/annurev.soc.24.1.183

Kosfeld, M., Heinrichs, M., Zak, P. J., Fischbacher, U., and Fehr, E. (2005). Oxytocin increases trust in humans. Nature 435, 673-676. doi: 10.1038/nature03701

Kugler, T., Kausel, E. E., and Kocher, M. G. (2012). Are groups more rational than individuals? A review of interactive decision making in groups. Wiley Interdiscip. Rev. Cogn. Sci. 3, 471-482. doi: 10.1002/wcs.1184

Kumru, C. S., and Vesterlund, L. (2010). The effect of status on charitable giving. J. Public Econ. Theory 12, 709-735. doi: 10.1111/j.1467-9779.2010.01471.x

Kuppens, P., Tuerlinckx, F., Russell, J. A., and Barrett, L. F. (2013). The relation between valence and arousal in subjective experience. Psychol. Bull. 139, 917-940. doi: 10.1037/a0030811

Lê, S., Josse, J., and Husson, F. (2008). FactoMineR: an R package for multivariate analysis. J. Stat. Softw. 25, 1-18. doi: 10.18637/jss.v025.i01

Lachman, M. E., and Weaver, S. L. (1998). The sense of control as a moderator of social class differences in health and well-being. J. Pers. Soc. Psychol. 74, 763-773. doi: 10.1037/0022-3514.74.3.763

Lammers, J., Galinsky, A. D., Gordijn, E. H., and Otten, S. (2008). Illegitimacy moderates the effects of power on approach. Psychol. Sci. 19, 558-564. doi: 10.1111/j.1467-9280.2008.02123.x

Lang, P. J., and Bradley, M. M. (2010). Emotion and the motivational brain. Biol. Psychol. 84, 437-450. doi: 10.1016/j.biopsycho.2009.10.007

Lea, S. E. G., and Webley, P. (2006). Money as tool, money as drug: the biological psychology of a strong incentive. Behav. Brain Sci. 29, 161-209. doi: 10.1017/S0140525X06009046

Lefcourt, H. M. (1991). "Locus of control," in Measures of Personality and Social Psychological Attitudes, eds P. Shaver, L. Wrightsman, and J. Robinson (New York, NY: Academic Press), 413-499. doi: 10.1371/journal.pone.0017798

Lerner, J. S., and Keltner, D. (2001). Fear, anger, and risk. J. Pers. Soc. Psychol. 81, 146-159. doi: 10.1037/0022-3514.81.1.146 
Lerner, J. S., Li, Y., Valdesolo, P., and Kassam, K. S. (2015). Emotion and decision making. Ann. Rev. Psychol. 66, 799-823. doi: 10.1146/annurev-psych-010213-115043

Lewin, K. (1935). A Dynamic Theory of Personality: Selected Papers. New York, NY: McGraw-Hill Book Co.

Liu, C., Chai, J. W., and Yu, R. (2016). Negative incidental emotions augment fairness sensitivity. Sci. Rep. 6:24892. doi: 10.1038/srep24892

Loewenstein, G. F., and O'Donoghue, T. (2004). Animal spirits: affective and deliberative processes in economic behavior. SSRN Electr. J. doi: $10.2139 /$ ssrn. 539843

Loewenstein, G. F., Thompson, L., and Bazerman, M. H. (1989). Social utility and decision making in interpersonal contexts. J. Pers. Soc. Psychol. 57:426. doi: 10.1037/0022-3514.57.3.426

Maner, J. K., and Gerend, M. A. (2007). Motivationally selective risk judgments: do fear and curiosity boost the boons or the banes? Organ. Behav. Hum. Decis. Process. 103, 256-267. doi: 10.1016/j.obhdp.2006.08.002

Maner, J. K., Luce, C. L., Neuberg, S. L., Cialdini, R. B., Brown, S., and Sagarin, B. J. (2002). The effects of perspective taking on motivations for helping: still no evidence for altruism. Pers. Soc. Psychol. Bull. 28, 1601-1610. doi: 10.1177/014616702237586

Mazur, A., and Booth, A. (1998). Testosterone and dominance in men. Behav. Brain Sci. 21, 353-363. doi: 10.1017/S0140525X98001228

McAdams, D. P. (1980). A thematic coding system for the intimacy motive. J. Res. Pers. 14, 413-432. doi: 10.1016/0092-6566(80)90001-X

McCall, C., and Singer, T. (2012). The animal and human neuroendocrinology of social cognition, motivation and behavior. Nat. Neurosci. 15, 681-688. doi: $10.1038 / \mathrm{nn} .3084$

McCall, C., Steinbeis, N., Ricard, M., and Singer, T. (2014). Compassion meditators show less anger, less punishment, and more compensation of victims in response to fairness violations. Front. Behav. Neurosci. 8:424. doi: $10.3389 /$ fnbeh.2014.00424

McClelland, D. C. (1965). Toward a theory of motive acquisition. Am. Psychol. 20, 321-333. doi: 10.1037/h0022225

McClelland, D. C., Atkinson, J. W., Clark, R. A., and Lowell, E. L. (1953). The Achievement Motive. East Norwalk, CT: Appleton-Century-Crofts.

McDougall, W. (1932). The Energies of Men (Psychology Revivals): A Study of the Fundamentals of Dynamic Psychology. London: Methuen.

Mehrabian, A. (1994). Evidence bearing on the affiliative tendency (MAFF) and sensitivity to rejection (MSR) scales. Curr. Psychol. 13, 97-116. doi: 10.1007/BF02686794

Montague, P. R., Hyman, S. E., and Cohen, J. D. (2004). Computational roles for dopamine in behavioural control. Nature 431, 760-767. doi: 10.1038 /nature03015

Moons, W. G., Eisenberger, N. I., and Taylor, S. E. (2010). Anger and fear responses to stress have different biological profiles. Brain Behav. Immun. 24, 215-219. doi: 10.1016/j.bbi.2009.08.009

Motro, D., Kugler, T., and Connolly, T. (2016). Back to the basics: how feelings of anger affect cooperation. Int. J. Conflict Manag. 27, 523-546. doi: 10.1108/IJCMA-10-2015-0068

Mowrer, O. H. (1960). Learning Theory and Behavior. Hoboken, NJ, US: John Wiley and Sons Inc.

Murray, H. A. (1938). Explorations in Personality. Oxford: Oxford University Press.

Nelson, D. L., McEvoy, C. L., and Schreiber, T. A. (2004). The University of South Florida free association, rhyme, and word fragment norms. Behav. Res. Methods Instruments Comput. 36, 402-407. doi: 10.3758/BF031 95588

Nelson, E. E., and Panksepp, J. (1998). Brain substrates of infant-mother attachment: contributions of opioids, oxytocin, and norepinephrine. Neurosci. Biobehav. Rev. 22, 437-452. doi: 10.1016/S0149-7634(97)00052-3

Nelson, R. J., and Trainor, B. C. (2007). Neural mechanisms of aggression. Nat. Rev. Neurosci. 8, 536-546. doi: 10.1038/nrn2174

O’Doherty, J., Kringelbach, M. L., Rolls, E. T., Hornak, J., and Andrews, C. (2001). Abstract reward and punishment representations in the human orbitofrontal cortex. Nat. Neurosci. 4, 95-102. doi: 10.1038/82959

Palfrey, T. R., and Rosenthal, H. (1988). Private incentives in social dilemmas. J. Public Econ. 35, 309-332. doi: 10.1016/0047-2727(88)90035-7

Pang, J. S. (2010). "The achievement motive: a review of theory and assessment of $\mathrm{n}$ achievement, hope of success, and fear of failure," in Implicit Motives, eds O. C. Schultheiss and J. C. Brunstein (Oxford: Oxford University Press), 30-70.

Panksepp, J. (2005). Affective consciousness: core emotional feelings in animals and humans. Conscious. Cogn. 14, 30-80. doi: 10.1016/j.concog.2004. 10.004

Panksepp, J. (2006). "The core emotional systems of the mammalian brain: the fundamental substrates of human emotions," in About a Body: Working With the Embodied Mind in Psychotherapy, eds J. Corrigall, H. Payne, and H. Wilkinson (London: Routledge), 14-32.

Pillutla, M. M., and Murnighan, J. K. (1996). Unfairness, anger, and spite: emotional rejections of ultimatum offers. Organ. Behav. Hum. Decis. Process. 68, 208-224. doi: 10.1006/obhd.1996.0100

Polman, E., and Kim, S. H. (2013). Effects of anger, disgust, and sadness on sharing with others. Pers. Soc. Psychol. Bull. 39, 1683-1692. doi: $10.1177 / 0146167213500998$

Porcelli, A. J., and Delgado, M. R. (2009). acute stress modulates risk taking in financial decision making. Psychol. Sci. 20, 278-283. doi: 10.1111/j.1467-9280.2009.02288.x

Posner, J., Russell, J. A., and Peterson, B. S. (2005). The circumplex model of affect: an integrative approach to affective neuroscience, cognitive development, and psychopathology. Dev. Psychopathol. 17, 715-734. doi: $10.1017 /$ S0954579405050340

Potegal, M., and Stemmler, G. (2010). "Constructing a neurology of anger," in International Handbook of Anger, eds M. Potegal, G. Stemmler, and C. Spielberger (New York, NY: Springer), 39-59.

Raghunathan, R., and Pham, M. T. (1999). All negative moods are not equal: motivational influences of anxiety and sadness on decision making. Organ. Behav. Hum. Decis. Process. 79, 56-77. doi: 10.1006/obhd.1999.2838

Rangel, A., Camerer, C., and Montague, P. R. (2008). A framework for studying the neurobiology of value-based decision making. Nat. Rev. Neurosci. 9, 545-556. doi: $10.1038 / \mathrm{nrn} 2357$

R-Core-Team (2014). R: A Language and Environment for Statistical Computing. Vienna: R Foundation for Statistical Computing. Retrieved from: http://www. r-project.org/.

Reimers, L., and Diekhof, E. K. (2015). Testosterone is associated with cooperation during intergroup competition by enhancing parochial altruism. Front. Neurosci. 9:183. doi: 10.3389/fnins.2015.00183

Reiss, S. (2004). Multifaceted nature of intrinsic motivation: the theory of 16 basic desires. Rev. Gen. Psychol. 8, 179-193. doi: 10.1037/1089-2680.8.3.179

Reuben, E., and van Winden, F. (2008). Social ties and coordination on negative reciprocity: the role of affect. J. Public Econ. 92, 34-53. doi: 10.1016/j.jpubeco.2007.04.012

Rheinberg, F., and Engeser, S. (2010). "Motive training and motivational competence," in Implicit Motives, eds O. C. Schultheiss and J. C. Brunstein (Oxford: Oxford University Press), 510-548.

Richie, R., White, B., Bhatia, S., and Hout, M. C. (2020). The spatial arrangement method of measuring similarity can capture highdimensional semantic structures. Behav. Res. Methods 52, 1906-1928. doi: 10.3758/s13428-020-01362-y

Rilling, J. K. (2013). The neural and hormonal bases of human parentalcare. Neuropsychologia 51, 731-747. doi: 10.1016/j.neuropsychologia.2012.12.017

Robson, A. J. (2001). The biological basis of economic behavior. J. Econ. Lit. 39, 11-33. doi: 10.1257/jel.39.1.11

Robson, A. J., and Samuelson, L. (2011). "The evolutionary foundations of preferences," in Handbook of Social Economics, eds J. Benhabib, A. Bisin, and M. O. Jackson (Amsterdam: Elsevier), 221-310.

Rodrigues, S. M., LeDoux, J. E., and Sapolsky, R. M. (2009). The influence of stress hormones on fear circuitry. Annu. Rev. Neurosci. 32, 289-313. doi: 10.1146/annurev.neuro.051508.135620

Roseman, I. J. (2011). Emotional behaviors, emotivational goals, emotion strategies: multiple levels of organization integrate variable and consistent responses. Emot. Rev. 3, 434-443. doi: 10.1177/1754073911410744

Ross, H. E., and Young, L. J. (2009). Oxytocin and the neural mechanisms regulating social cognition and affiliative behavior. Front. Neuroendocrinol. 30, 534-547. doi: 10.1016/j.yfrne.2009.05.004

Ruff, C. C., Ugazio, G., and Fehr, E. (2013). Changing social norm compliance with noninvasive brain stimulation. Science 342, 482-484. doi: $10.1126 /$ science. 1241399 
Russell, J. A. (1980). A circumplex model of affect. J. Pers. Soc. Psychol. 39, 1161-1178. doi: $10.1037 / \mathrm{h} 0077714$

Sally, D. (2001). On sympathy and games. J. Econ. Behav. Org. 44, 1-30. doi: 10.1016/S0167-2681(00)00153-0

Salvador, A. (2005). Coping with competitive situations in humans. Neurosci. Biobehav. Rev. 29, 195-205. doi: 10.1016/j.neubiorev.2004. 07.004

Samuelson, P. A. (1938). A note on the pure theory of consumer's behaviour. Economica 5:61. doi: 10.2307/2548836

Schulreich, S., Gerhardt, H., and Heekeren, H. R. (2016). Incidental fear cues increase monetary loss aversion. Emotion 16:402. doi: 10.1037/emo00 00124

Schultheiss, O. C., and Brunstein, J. C. (2010). Implicit Motives. Oxford: Oxford University Press.

Schultheiss, O. C., and Strasser, A. (2012). "Referential processing and competence as determinants of congruence between implicit and explicit motives," in Handbook of Self-Knowledge, eds S. Vazire and T. D. Wilson (New York, NY: Guilford), 39-62.

Schultz, W. (2007). Behavioral dopamine signals. Trends Neurosci. 30, 203-210. doi: 10.1016/j.tins.2007.03.007

Schwartz, S. H., and Boehnke, K. (2004). Evaluating the structure of human values with confirmatory factor analysis. J. Res. Pers. 38, 230-255. doi: 10.1016/S0092-6566(03)00069-2

Seip, E. C., Van Dijk, W. W., and Rotteveel, M. (2014). Anger motivates costly punishment of unfair behavior. Motiv. Emot. 38, 578-588. doi: 10.1007/s11031-014-9395-4

Selten, R. (1998). Aspiration adaptation theory. J. Math. Psychol. 42, 191-214. doi: 10.1006/jmps.1997.1205

Seymour, B., and Dolan, R. (2008). Emotion, decision making, and the amygdala. Neuron 58, 662-671. doi: 10.1016/j.neuron.2008.05.020

Seymour, B., Singer, T., and Dolan, R. (2007). The neurobiology of punishment. Nat. Rev. Neurosci. 8, 300-311. doi: 10.1038/nrn2119

Shang, J., and Croson, R. (2009). A field experiment in charitable contribution: the impact of social information on the voluntary provision of public goods. Econ. J. 119, 1422-1439. doi: 10.1111/j.1468-0297.2009.02267.x

Shaver, P., Schwartz, J., Kirson, D., and O'Connor, C. (1987). Emotion knowledge: further exploration of a prototype approach. J. Pers. Soc. Psychol. 52, 1061-1086. doi: $10.1037 / 0022-3514.52 .6 .1061$

She, S., Eimontaite, I., Zhang, D., and Sun, Y. (2017). Fear, anger, and risk preference reversals: an experimental study on a Chinese sample. Front. Psychol. 8:1371. doi: 10.3389/fpsyg.2017.01371

Siever, L. J. (2008). Neurobiology of aggression and violence. Am. J. Psychiatry 165, 429-442. doi: 10.1176/appi.ajp.2008.07111774

Singer, T., and Klimecki, O. M. (2014). Empathy and compassion. Curr. Biol. 24, R875-R878. doi: 10.1016/j.cub.2014.06.054

Singer, T., and Steinbeis, N. (2009). Differential roles of fairness- and compassion-based motivations for cooperation, defection, and punishment. Ann. N. Y. Acad. Sci. 1167, 41-50. doi: 10.1111/j.1749-6632.2009. 04733.x

Small, D. A., and Lerner, J. S. (2008). Emotional policy: personal sadness and anger shape judgments about a welfare case. Polit. Psychol. 29, 149-168. doi: 10.1111/j.1467-9221.2008.00621.x

Spielberger, C. D. (2010). State-Trait Anxiety Inventory The Corsini Encyclopedia of Psychology. Hoboken, NJ: John Wiley and Sons, Inc.

Spitzer, M., Fischbacher, U., Herrnberger, B., Grön, G., and Fehr, E. (2007). The neural signature of social norm compliance. Neuron 56, 185-196. doi: 10.1016/j.neuron.2007.09.011

Stanton, S. J., Mullette-Gillman, O. D. A., McLaurin, R. E., Kuhn, C. M., LaBar, K. S., Platt, M. L., et al. (2011). Low- and high-testosterone individuals exhibit decreased aversion to economic risk. Psychol. Sci. 22, 447-453. doi: $10.1177 / 0956797611401752$

Stemmler, G. (2004). Physiological Processes During Emotion The Regulation of Emotion. New York, NY: Psychology Press, 48-85.

Stemmler, G., Aue, T., and Wacker, J. (2007). Anger and fear: separable effects of emotion and motivational direction on somatovisceral responses. Int. J. Psychophysiol. 66, 141-153. doi: 10.1016/j.ijpsycho.2007.03.019

Stigler, G. J., and Becker, G. S. (1977). De Gustibus non est disputandum. Am. Econ. Rev. 67, 76-90.
Strathearn, L., Fonagy, P., Amico, J., and Montague, P. R. (2009). Adult attachment predicts maternal brain and oxytocin response to infant cues. Neuropsychopharmacology 34, 2655-2666. doi: 10.1038/npp.2009.103

Straub, P. G., and Murnighan, J. K. (1995). An experimental investigation of ultimatum games: information, fairness, expectations, and lowest acceptable offers. J. Econ. Behav. Organ. 27, 345-364. doi: 10.1016/0167-2681(94)00072-M

Takahashi, T., Ikeda, K., and Hasegawa, T. (2007). Social evaluation-induced amylase elevation and economic decision-making in the dictator game in humans. Neuroendocrinol. Lett. 28, 662-665.

Talevich, J. R., Read, S. J., Walsh, D. A., Iyer, R., and Chopra, G. (2017). Toward a comprehensive taxonomy of human motives. PLoS ONE 12:e0172279. doi: 10.1371/journal.pone.0172279

Taylor, S. E. (2006). Tend and befriend: biobehavioral bases of affiliation under stress. Curr. Dir. Psychol. Sci. 15, 273-277. doi: $10.1111 / j .1467-8721.2006 .00451 . x$

Terburg, D., and van Honk, J. (2013). Approach-avoidance versus dominancesubmissiveness: a multilevel neural framework on how testosterone promotes social status. Emot. Rev. 5, 296-302. doi: 10.1177/1754073913477510

Thorndike, E. L. (1898). Animal intelligence: an experimental study of the associative processes in animals. Psychol. Rev. Monogr. Suppl. 2:i-109. doi: $10.1037 / \mathrm{h} 0092987$

Trudewind, C. (2000). "Curiosity and anxiety as motivational determinants of cognitive development," in Motivational Psychology of Human Development: Developing Motivation and Motivating Development, ed J. Heckhausen (New York, NY: Elsevier), 15-38.

Tsai, M. H., and Young, M. J. (2010). Anger, fear, and escalation of commitment. Cogn. Emot. 24, 962-973. doi: 10.1080/02699930903050631

Tusche, A., Böckler, A., Kanske, P., Trautwein, F. M., and Singer, T. (2016). Decoding the charitable brain: empathy, perspective taking, and attention shifts differentially predict altruistic giving. J. Neurosci. 36, 4719-4732. doi: 10.1523/JNEUROSCI.3392-15.2016

Valk, S. L., Bernhardt, B. C., Trautwein, F.-M., Böckler, A., Kanske, P., Guizard, N., et al. (2017). Structural plasticity of the social brain: differential change after socio-affective and cognitive mental training. Sci. Adv. 3:e1700489. doi: $10.1126 /$ sciadv. 1700489

van Honk, J., Will, G.-J., Terburg, D., Raub, W., Eisenegger, C., and Buskens, V. (2016). Effects of testosterone administration on strategic gambling in poker play. Sci. Rep. 6:18096. doi: 10.1038/srep18096

van Hoorn, J., Fuligni, A. J., Crone, E. A., and Galvan, A. (2016). Peer influence effects on risk-taking and prosocial decision-making in adolescence: insights from neuroimaging studies. Curr. Opin. Behav. Sci. 10, 59-64. doi: 10.1016/j.cobeha.2016.05.007

van Lange, P. A. M., Joireman, J., Parks, C. D., and Van Dijk, E. (2013). The psychology of social dilemmas: a review. Organ. Behav. Hum. Decis. Process. 120, 125-141. doi: 10.1016/j.obhdp.2012.11.003

Veling, H., Ruys, K. I., and Aarts, H. (2011). Anger as a hidden motivator. Soc. Psychol. Personal. Sci. 3, 438-445. doi: 10.1177/1948550611425425

von Dawans, B., Fischbacher, U., Kirschbaum, C., Fehr, E., and Heinrichs, M. (2012). The social dimension of stress reactivity: acute stress increases prosocial behavior in humans. Psychol. Sci. 23, 651-660. doi: 10.1177/0956797611431576 Wedekind, C., and Milinski, M. (2000). Cooperation through image scoring in humans. Science 288, 850-852. doi: 10.1126/science.288.5467.850

Weinberger, J., Cotler, T., and Fishman, D. (2010). "The duality of affiliative motivation," in Implicit Motives, eds O. C. Schultheiss and J. C. Brunstein (Oxford: Oxford University Press), 71-88.

Weiner, B. (1990). History of motivational research in education. J. Educ. Psychol. 82, 616-622. doi: 10.1037/0022-0663.82.4.616

Weng, H. Y., Fox, A. S., Shackman, A. J., Stodola, D. E., Caldwell, J. Z. K., Olson, M. C., et al. (2013). Compassion training alters altruism and neural responses to suffering. Psychol. Sci. 24, 1171-1180. doi: 10.1177/0956797612 469537

Wingfield, J. C., Hegner, R. E., Dufty Jr, A. M., and Ball, G. F. (1990). The "challenge hypothesis": theoretical implications for patterns of testosterone secretion, mating systems, and breeding strategies. Am. Nat. 136, 829-846. doi: $10.1086 / 285134$

Winking, J., and Mizer, N. (2013). Natural-field dictator game shows no altruistic giving. Evol. Hum. Behav. 34, 288-293. doi: 10.1016/j.evolhumbehav.2013.04.002 
Yamagishi, T., Horita, Y., Mifune, N., Hashimoto, H., Li, Y., Shinada, M., et al. (2012). Rejection of unfair offers in the ultimatum game is no evidence of strong reciprocity. Proc. Natl. Acad. Sci. U.S.A. 109, 20364-20368. doi: 10.1073/pnas.12121 26109

Yamagishi, T., and Mifune, N. (2016). Parochial altruism: does it explain modern human group psychology? Curr. Opin. Psychol. 7, 39-43. doi: 10.1016/j.copsyc.2015.07.015

Zaki, J., Schirmer, J., and Mitchell, J. P. (2011). Social influence modulates the neural computation of value. Psychol. Sci. 22. 894-900. doi: $10.1177 / 0956797611411057$
Conflict of Interest: The authors declare that the research was conducted in the absence of any commercial or financial relationships that could be construed as a potential conflict of interest.

Copyright (c) 2021 Chierchia, Przyrembel, Lesemann, Bosworth, Snower and Singer. This is an open-access article distributed under the terms of the Creative Commons Attribution License (CC BY). The use, distribution or reproduction in other forums is permitted, provided the original author(s) and the copyright owner(s) are credited and that the original publication in this journal is cited, in accordance with accepted academic practice. No use, distribution or reproduction is permitted which does not comply with these terms. 